The Federal Reserve BanK of Kansas City Research Working Papers

\title{
Trend Inflation and
}

Equilibrium Stability: FirmSpecific versus Homogenous Labor

Takushi Kurozumi and Willem Van Zandweghe December 2012; Revised August 2015

RWP 12-09 


\title{
TREND INFLATION AND EQUILIBRIUM STABILITY: FIRM-SPECIFIC VERSUS HOMOGENEOUS LABOR*
}

\author{
TAKUSHI KUROZUMI \\ Bank of Japan \\ WILLEM VAN ZANDWEGHE \\ Federal Reserve Bank of Kansas City
}

\begin{abstract}
In sticky price models based on micro evidence that each period a fraction of prices is kept unchanged, recent studies reach the qualitatively same conclusion that higher trend inflation is a more serious source of indeterminacy of rational expectations equilibrium, regardless of whether labor is firm-specific or homogeneous. This paper shows that the model with firm-specific labor is more susceptible to indeterminacy induced by high trend inflation than the model with homogeneous labor, because these two different specifications of labor lead to distinct representations of inflation dynamics. In addition, the model with firm-specific labor is more susceptible to expectational instability of the equilibrium caused by high trend inflation.
\end{abstract}

Keywords: Trend inflation, Firm-specific versus homogeneous labor, Inflation dynamics, Equilibrium determinacy, Expectational stability

\footnotetext{
*The authors are grateful to the editor William Barnett, Olivier Coibion, Andrew Foerster, an associate editor, two anonymous referees, and participants at the Midwest Macroeconomics Meetings 2012 and a seminar at the Federal Reserve Bank of Kansas City for comments and discussions. The views expressed herein are those of the authors and should not be interpreted as those of the Bank of Japan, the Federal Reserve Bank of Kansas City or the Federal Reserve System. Address correspondence to: Willem Van Zandweghe, Research Department, Federal Reserve Bank of Kansas City, 1 Memorial Drive, Kansas City, MO 64198, USA; e-mail: willem.vanzandweghe@kc.frb.org.
} 


\section{INTRODUCTION}

Recent research has studied implications of a non-zero rate of trend inflation for macroeconomic stability in sticky price models based on micro evidence that each period a fraction of prices is kept unchanged. ${ }^{1}$ Ascari and Ropele (2009) and Coibion and Gorodnichenko (2011) investigate the implications for determinacy of rational expectations equilibrium (REE) under the Taylor (1993) rule in a Calvo (1983) sticky price model. ${ }^{2}$ These studies reach the qualitatively same conclusion that higher trend inflation is a more serious source of indeterminacy, regardless of whether labor is firm-specific or homogeneous. Moreover, Coibion and Gorodnichenko argue that a decline in trend inflation, along with an increase in the Federal Reserve's policy response to inflation, explains much of the U.S. economy's shift from indeterminacy in the Great Inflation era to determinacy in the Great Moderation era. This argument contrasts with Clarida et al. (2000) and Lubik and Schorfheide (2004), who all attribute the U.S. economy's shift solely to the Federal Reserve's switch from a passive to an active policy response to inflation.

The two different specifications of labor-firm-specific versus homogeneous labor-lead to distinct representations of inflation dynamics. In the model with firm-specific labor, Coibion and Gorodnichenko (2011) derive a generalized New Keynesian Phillips curve (GNKPC) and show that this GNKPC solely represents inflation dynamics even at a non-zero rate of trend inflation. Ascari and Ropele (2009) analyze the model with homogeneous labor and demonstrate that inflation dynamics is represented not only by a GNKPC but also by the law of motion of price distortion, as long as the trend inflation rate is non-zero and the elasticity of labor supply is finite. The distinct representations of inflation dynamics generate three implications concerning equilibrium stability. First, firm-specific labor introduces strategic complementarity in price setting, as indicated in previous studies including Bakhshi et al. (2007). ${ }^{3}$ The

\footnotetext{
${ }^{1}$ Ascari and Sbordone (2014) review this strand of literature. For recent micro evidence on price adjustment, see, e.g., Kehoe and Midrigan (2015), Klenow and Kryvtsov (2008), Klenow and Malin (2010), and Nakamura and Steinsson (2008).

${ }^{2}$ In analyzing determinacy of REE under the Taylor rule, Arias (2013) uses a Calvo sticky price model with capital accumulation and sticky wages, while Hornstein and Wolman (2005) and Kiley (2007) employ a Taylor (1980) sticky price model. Ascari and Ropele (2007) examine the implications for determinacy of REE under an optimal monetary policy in a Calvo sticky price model.

${ }^{3}$ Firm-specific capital also incorporates strategic complementarity, as pointed out by Altig et al. (2011), Eichenbaum and Fisher (2007), Sveen and Weinke (2005, 2007), and Woodford (2005). See also Levin et al. (2008) for monetary policy implications of strategic complementarity.
} 
resulting GNKPC contains a flatter slope (i.e., a smaller elasticity of inflation with respect to output) than in the model with homogeneous labor. As a consequence, inflation is less sensitive to output and thereby monetary policy is less capable of stabilizing inflation in the model with firm-specific labor. Second, in relation to the difference in the slope of the GNKPC, the long-run inflation elasticity of output implied by the GNKPC differs between the models with firm-specific and homogeneous labor. As pointed out by previous studies, such as Ascari and Ropele (2009) and Kurozumi (2011, 2014), this elasticity plays a key role in the equilibrium stability condition called the long-run version of the Taylor principle (i.e., in the long run the interest rate should be raised by more than the increase in inflation). ${ }^{4}$ Third, when labor is homogeneous and the elasticity of labor supply is finite, the law of motion of price distortion is one of the equilibrium conditions relevant to equilibrium stability at a non-zero rate of trend inflation. Then, the persistence of price distortion generates endogenously persistent inflation dynamics. Despite these three implications generated by the distinct representations of inflation dynamics, the existing literature lacks a comparison between the models with firm-specific and homogeneous labor in terms of stability of REE in sticky price models.

The present paper fills this gap using a Calvo sticky price model. Specifically, our paper compares implications of a non-zero rate of trend inflation for determinacy of REE under the Taylor rule between the models with firm-specific and homogeneous labor. The paper also examines and compares the implications for expectational stability (E-stability) of fundamental REE under the Taylor rule. ${ }^{5}$ As McCallum (2007) indicates, E-stability is very closely linked with least-squares learnability (i.e., stability under least-squares learning) and this learnability is arguably a necessary property for an REE to be plausible as equilibrium for the model at hand. In a broad class of linear models with expectations (including our log-linearized models), a non-explosive fundamental REE is least-squares learnable if it is E-stable; otherwise, it is not

\footnotetext{
${ }^{4}$ Kurozumi (2011) shows that indeterminacy caused by higher trend inflation is less prevalent when price stickiness is endogenously determined in a Calvo model along the lines of previous studies, such as Ball et al. (1988), Romer (1990), Kiley (2000), Devereux and Yetman (2002), Levin and Yun (2007), and Kimura and Kurozumi (2010). This is because the long-run inflation elasticity of output declines substantially with higher trend inflation in the case of exogenously given price stickiness, whereas in the case of endogenous price stickiness the decline in the elasticity is mitigated because higher trend inflation leads to a higher probability of price adjustment.

${ }^{5}$ The term "fundamental" refers to Evans and Honkapohja (2001)'s minimal-state-variable (MSV) solutions to linear rational expectations models to distinguish them from McCallum (1983)'s original MSV solution.
} 
least-squares learnable (Evans and Honkapohja, 2001). Therefore, E-stability is an essential condition for an REE to be regarded as plausible. ${ }^{6}$

The paper shows that the model with firm-specific labor is more susceptible to indeterminacy of the REE caused by high trend inflation than the model with homogeneous labor. Moreover, the former model is more susceptible to E-instability of the fundamental REE induced by high trend inflation. These indeterminacy and E-instability results are robust with respect to the specification of the Taylor rule, such as not only a standard outcome-based rule (that responds to contemporaneous values of inflation and output) but also a forecastbased rule and outcome-based rules with policy rate smoothing and with responses to output growth. Accordingly, the argument of Coibion and Gorodnichenko (2011) - a decline in trend inflation plays a key role in the U.S. economy's shift from the Great Inflation era to the Great Moderation era-could depend crucially on their assumption of firm-specific labor.

Our indeterminacy result is obtained because two key conditions for determinacy are more restrictive in the model with firm-specific labor than in the model with homogeneous labor. One condition is the long-run version of the Taylor principle. Higher trend inflation lowers the long-run inflation elasticity of output and thereby makes the condition more restrictive for the Taylor rule's coefficients on inflation and output. Once the trend inflation rate is higher than a certain threshold that is positive but close to zero, the strategic complementarity incorporated by firm-specific labor causes the elasticity in this model to be lower than that in the model with homogeneous labor, and thus the condition is more restrictive in the model with firm-specific labor. Then, for a stronger policy response to output, the condition calls for a stronger policy response to inflation. As a consequence, when the policy response to output is strong, a policy response to inflation that ensures determinacy in the model with homogeneous labor can induce indeterminacy in the model with firm-specific labor. The other condition for determinacy requires a stronger policy response to inflation for a weaker policy response to output at a positive rate of trend inflation. This condition is more restrictive when the slope of the GNKPC is smaller. Because the strategic complementarity makes the slope in the model with firm-specific labor lower than that in the model with homogeneous labor, as noted above,

\footnotetext{
${ }^{6}$ As emphasized in Bullard and Mitra (2002), a considerable amount of research presupposes implicitly that if there is a determinate REE then all agents can coordinate on that REE, but it is far from clear exactly how or whether such coordination would arise. Least-squares learnability (and hence E-stability) is thus a necessary additional criterion for evaluating stability of REE.
} 
the condition is more restrictive in the former model. Consequently, when the policy response to output is weak, a policy response to inflation that guarantees determinacy in the model with homogeneous labor can cause indeterminacy in the model with firm-specific labor.

Our E-instability result arises for two reasons. First, the long-run version of the Taylor principle is a necessary condition for E-stability of the fundamental REE in the model with firm-specific labor, whereas it is not always in the model with homogeneous labor, i.e., even if it is not satisfied, the fundamental REE can be E-stable. When trend inflation is higher than the threshold mentioned above, the long-run version of the Taylor principle is more restrictive for the Taylor rule's coefficients on inflation and output, and thus the model with firm-specific labor is more susceptible to E-instability. Second, when labor is homogeneous, price distortion appears in the GNKPC and its persistence generates endogenously persistent inflation dynamics, as long as the trend inflation rate is non-zero and the elasticity of labor supply is finite. For the REE in question, E-stability examines whether an associated equilibrium in which agents form expectations under adaptive learning reaches over time that REE. Under such expectation formation, the endogenous persistence of inflation dynamics through the law of motion of price distortion helps agents form inflation expectations and learn the fundamental REE in the model with homogeneous labor. By contrast, this is not the case in the model with firm-specific labor. Price distortion is absent in the GNKPC and thus higher trend inflation is a more serious source of E-instability. ${ }^{7}$ Therefore, E-instability caused by high trend inflation is more prevalent when labor is firm-specific.

The remainder of the paper proceeds as follows. Section 2 describes Calvo sticky price models with firm-specific labor and with homogeneous labor. Between these two models, Section 3 and 4 compare determinacy of REE and E-stability of fundamental REE, respectively. Section 5 conducts some robustness exercises. Section 6 concludes.

\footnotetext{
${ }^{7}$ Kobayashi and Muto (2013) use a Calvo sticky price model with homogeneous labor based on Sbordone (2007) and Cogley and Sbordone (2008), but their model follows Sbordone (2007) to assume that real marginal cost does not reflect cost arising from price distortion. Because of this assumption, price distortion never appears in their GNKPC. Consequently, they conclude that when trend inflation is high, E-instability is prevalent. This is qualitatively consistent with our E-instability result in the model with firm-specific labor, but not with that in the model with homogeneous labor.
} 


\section{CALVO STICKY PRICE MODELS WITH FIRM-SPECIFIC LABOR AND WITH HOMOGENEOUS LABOR}

This section begins by describing a Calvo sticky price model with firm-specific labor and then presents its associated model with homogeneous labor.

\subsection{Model with Firm-Specific Labor}

The model with firm-specific labor is based on Coibion and Gorodnichenko (2011). In the economy there are a representative household, a representative final-good firm, a continuum of intermediate-good firms, and a monetary authority. The household's members supply labor specific to intermediate-good firms. The behavior of each agent is described in turn.

\subsubsection{Household}

The representative household consumes $C_{t}$ final goods, supplies $\left\{N_{t}(i)\right\}$ labor specific to each intermediate-good firm $i \in[0,1]$, and purchases $S_{t}$ one-period riskless bonds so as to maximize the utility function $E_{0} \sum_{t=0}^{\infty} \beta^{t}\left\{\ln C_{t}-[1 /(1+1 / \eta)] \int_{0}^{1}\left(N_{t}(i)\right)^{1+1 / \eta} d i\right\} \exp \left(\varepsilon_{t}\right)$ subject to the budget constraint $P_{t} C_{t}+S_{t}=\int_{0}^{1} W_{t}(i) N_{t}(i) d i+R_{t-1} S_{t-1}+T_{t}$, where $E_{t}$ is the rational expectation operator conditional on information available in period $t, \beta \in(0,1)$ is the subjective discount factor, $\eta>0$ is the elasticity of labor supply, $\varepsilon_{t}$ is a preference shock governed by a first-order autoregression process with a persistence parameter $\rho \in[0,1), P_{t}$ is the price of final goods, $W_{t}(i)$ is the wage paid by intermediate-good firm $i, R_{t}$ is the gross interest rate on bonds, and $T_{t}$ consists of lump-sum transfers and firm profits.

Combining first-order conditions for utility maximization with respect to consumption, labor supply, and bond holdings yields

$$
\begin{aligned}
\frac{W_{t}(i)}{P_{t}} & =C_{t}\left(N_{t}(i)\right)^{1 / \eta}, \\
1 & =E_{t}\left(\beta \frac{C_{t} \exp \left(\varepsilon_{t+1}\right)}{C_{t+1} \exp \left(\varepsilon_{t}\right)} \frac{R_{t}}{\Pi_{t+1}}\right),
\end{aligned}
$$

where $\Pi_{t}=P_{t} / P_{t-1}$ denotes the gross inflation rate of final goods' price.

\subsubsection{Firms}

The representative final-good firm produces $Y_{t}$ homogeneous goods under perfect competition by choosing $\left\{Y_{t}(i)\right\}$ intermediate inputs so as to maximize profit $P_{t} Y_{t}-\int_{0}^{1} P_{t}(i) Y_{t}(i) d i$ subject 
to the CES production technology $Y_{t}=\left[\int_{0}^{1}\left(Y_{t}(i)\right)^{(\theta-1) / \theta} d i\right]^{\theta /(\theta-1)}$, where $P_{t}(i)$ is the price of intermediate good $i$ and $\theta>1$ is the price elasticity of demand for each intermediate good.

The first-order condition for profit maximization yields the final-good firm's demand for intermediate good $i$,

$$
Y_{t}(i)=Y_{t}\left(\frac{P_{t}(i)}{P_{t}}\right)^{-\theta}
$$

Then, the CES production technology leads to

$$
P_{t}=\left[\int_{0}^{1}\left(P_{t}(i)\right)^{1-\theta} d i\right]^{1 /(1-\theta)} .
$$

The final-good market clearing condition is given by

$$
Y_{t}=C_{t}
$$

Each intermediate-good firm $i$ produces one kind of differentiated goods $Y_{t}(i)$ under monopolistic competition. Firm $i$ 's production function is given by

$$
Y_{t}(i)=A_{t}\left(N_{t}(i)\right)^{\alpha}
$$

where $\alpha \in(0,1]$ is the labor elasticity of output and the technology level $A_{t}$ follows

$$
\ln A_{t}=g+\ln A_{t-1}
$$

where $g$ is the rate of technological change.

The first-order condition for production cost minimization determines firm $i$ 's marginal cost

$$
M C_{t}(i)=\frac{W_{t}(i) N_{t}(i)}{\alpha Y_{t}(i)}
$$

In the face of the final-good firm's demand (3) and marginal cost (8), intermediate-good firms set prices of their products on a staggered basis as in Calvo (1983). In each period, a fraction $\lambda \in(0,1)$ of firms keeps previous-period prices unchanged, while the remaining fraction $1-\lambda$ of firms sets the price $B_{t}(i)$ so as to maximize the profit function $E_{t} \sum_{j=0}^{\infty} \lambda^{j} Q_{t, t+j} Y_{t+j}\left(B_{t}(i) / P_{t+j}\right)^{-\theta}\left(B_{t}(i)-M C_{t+j}(i)\right)$, where $Q_{t, t+j}=\beta^{j} P_{t} C_{t} \exp \left(\varepsilon_{t+j}\right) /\left(P_{t+j} C_{t+j} \exp \left(\varepsilon_{t}\right)\right)$ is the nominal stochastic discount factor between period $t$ and period $t+j$. For this profit function to be well-defined, the following assumption is imposed throughout the paper.

Assumption 1 The two inequalities $\lambda \bar{\Pi}^{\theta-1}<1$ and $\beta \lambda \bar{\Pi}^{\theta \gamma}<1$ hold, where $\bar{\Pi}$ is the gross rate of trend inflation (i.e., the steady-state value of final goods' price inflation rate $\Pi_{t}$ ) and $\gamma=(1+1 / \eta) / \alpha(\geq 1)$. Moreover, the trend inflation rate is non-negative, i.e., $\bar{\Pi} \geq 1$. 
Using eqs. (1), (3), (5), (6), and (8), the first-order condition for staggered price-setting leads to

$$
E_{t} \sum_{j=0}^{\infty}(\beta \lambda)^{j} \exp \left(\varepsilon_{t+j}\right)\left[\left(\frac{B_{t}}{P_{t+j}}\right)^{1-\theta}-\frac{\theta}{\alpha(\theta-1)}\left(\frac{Y_{t+j}}{A_{t+j}}\right)^{\gamma}\left(\frac{B_{t}}{P_{t+j}}\right)^{-\theta \gamma}\right]=0,
$$

where $B_{t}$ is the price set by firms that reoptimize prices in period $t$. Moreover, final goods' price equation (4) can be reduced to

$$
\left(P_{t}\right)^{1-\theta}=(1-\lambda)\left(B_{t}\right)^{1-\theta}+\lambda\left(P_{t-1}\right)^{1-\theta} .
$$

\subsubsection{Monetary Authority}

The monetary authority conducts interest rate policy according to the Taylor (1993) rule. The interest rate $R_{t}$ is adjusted in response to deviations of inflation $\Pi_{t}$ and output $Y_{t}$ from their trend levels

$$
\ln R_{t}=\ln R+\phi_{\pi}\left(\ln \Pi_{t}-\ln \bar{\Pi}\right)+\phi_{y}\left[\ln \left(Y_{t} / A_{t}\right)-\ln y\right]
$$

where $R$ is the gross steady-state interest rate, $y$ is the steady-state level of detrended output $y_{t}=Y_{t} / A_{t}$, and $\phi_{\pi}, \phi_{y} \geq 0$ are the degrees of policy responses to inflation and output.

\subsubsection{Log-Linearized Equilibrium Conditions}

From eqs. (2), (5), (9), (10), and (11), Appendix A presents equilibrium conditions and the steady state of the model with firm-specific labor in terms of stationary variables. Under Assumption 1, the log-linearized model is given by

$$
\begin{aligned}
\hat{y}_{t}= & E_{t} \hat{y}_{t+1}-\left(\hat{R}_{t}-E_{t} \hat{\Pi}_{t+1}\right)+\varepsilon_{t}-E_{t} \varepsilon_{t+1}, \\
\hat{\Pi}_{t}-\beta \lambda \bar{\Pi}^{\theta \gamma} E_{t} \hat{\Pi}_{t+1}= & \beta\left(E_{t} \hat{\Pi}_{t+1}-\beta \lambda \bar{\Pi}^{\theta \gamma} E_{t} \hat{\Pi}_{t+2}\right)+\kappa_{f}\left(\hat{y}_{t}-\beta \lambda \bar{\Pi}^{\theta-1} E_{t} \hat{y}_{t+1}\right) \\
& +\frac{\beta\left(\bar{\Pi}^{1+\theta(\gamma-1)}-1\right)\left(1-\lambda \bar{\Pi}^{\theta-1}\right)}{1+\theta(\gamma-1)}\left(\theta \gamma E_{t} \hat{\Pi}_{t+1}-\varepsilon_{t}+E_{t} \varepsilon_{t+1}\right), \\
\hat{R}_{t}= & \phi_{\pi} \hat{\Pi}_{t}+\phi_{y} \hat{y}_{t},
\end{aligned}
$$

where $\kappa_{f}=\gamma\left(1-\lambda \bar{\Pi}^{\theta-1}\right)\left(1-\beta \lambda \bar{\Pi}^{\theta \gamma}\right) /\left\{\lambda \bar{\Pi}^{\theta-1}[1+\theta(\gamma-1)]\right\} \geq 0$ represents the slope of the GNKPC (13) and all hatted variables denote log-deviations from steady-state values. ${ }^{8}$

\footnotetext{
${ }^{8}$ See Appendix B for the derivation of the GNKPC (13).
} 
Eq. (13) presents a GNKPC, because at a zero rate of trend inflation (i.e., $\bar{\Pi}=1$ ), the resulting equation can be reduced to

$$
\hat{\Pi}_{t}=\beta E_{t} \hat{\Pi}_{t+1}+\kappa_{f, 0} \hat{y}_{t}=\beta E_{t} \hat{\Pi}_{t+1}+\frac{\gamma(1-\lambda)(1-\beta \lambda)}{\lambda[1+\theta(\gamma-1)]} \hat{y}_{t} .
$$

\subsection{Model with Homogeneous Labor}

When labor is homogeneous, the model is based on Ascari and Ropele (2009). The representative household's utility function is given by $E_{0} \sum_{t=0}^{\infty} \beta^{t}\left\{\ln C_{t}-[1 /(1+1 / \eta)] N_{t}^{1+1 / \eta}\right\} \exp \left(\varepsilon_{t}\right)$, and the budget constraint is given by $P_{t} C_{t}+S_{t}=W_{t} N_{t}+R_{t-1} S_{t-1}+T_{t}$, where $N_{t}$ is the supply of homogeneous labor and $W_{t}$ is its wage. Combining first-order conditions for utility maximization with respect to consumption and labor supply yields

$$
\frac{W_{t}}{P_{t}}=C_{t} N_{t}^{1 / \eta}
$$

The first-order condition for intermediate-good firm $i$ 's production cost minimization determines its marginal cost

$$
M C_{t}(i)=\frac{W_{t} N_{t}(i)}{\alpha Y_{t}(i)}
$$

The labor market clearing condition is given by $N_{t}=\int_{0}^{1} N_{t}(i) d i$. Using this equation and eqs. (3), (5), (6), (15), and (16), the first-order condition for staggered price-setting leads to

$$
E_{t} \sum_{j=0}^{\infty}(\beta \lambda)^{j} \exp \left(\varepsilon_{t+j}\right)\left[\left(\frac{B_{t}}{P_{t+j}}\right)^{1-\theta}-\frac{\theta}{\alpha(\theta-1)}\left(\frac{Y_{t+j}}{A_{t+j}}\right)^{\gamma}\left(\frac{B_{t}}{P_{t+j}}\right)^{-\theta / \alpha} d_{t+j}^{1 / \eta}\right]=0
$$

where $d_{t}=\int_{0}^{1}\left(P_{t}(i) / P_{t}\right)^{-\theta / \alpha} d i$ represents price distortion and evolves according to

$$
P_{t}^{-\theta / \alpha} d_{t}=(1-\lambda) B_{t}^{-\theta / \alpha}+\lambda P_{t-1}^{-\theta / \alpha} d_{t-1}
$$

From eqs. (17) and (18) in addition to eqs. (2), (5), (10), and (11), Appendix A presents equilibrium conditions and the steady state of the model with homogeneous labor in terms of stationary variables. Under Assumption 1, the log-linearized model is given by eqs. (12), (14), and

$$
\begin{aligned}
\hat{\Pi}_{t}-\beta \lambda \bar{\Pi}^{\theta / \alpha} E_{t} \hat{\Pi}_{t+1}= & \beta\left(E_{t} \hat{\Pi}_{t+1}-\beta \lambda \bar{\Pi}^{\theta / \alpha} E_{t} \hat{\Pi}_{t+2}\right)+\kappa_{h}\left[\hat{y}_{t}+\frac{1}{\eta \gamma} \hat{d}_{t}-\beta \lambda \bar{\Pi}^{\theta-1}\left(E_{t} \hat{y}_{t+1}+\frac{1}{\eta \gamma} E_{t} \hat{d}_{t+1}\right)\right] \\
& +\frac{\beta\left(\bar{\Pi}^{1+\theta(1 / \alpha-1)}-1\right)\left(1-\lambda \bar{\Pi}^{\theta-1}\right)}{1+\theta(1 / \alpha-1)}\left(\frac{\theta}{\alpha} E_{t} \hat{\Pi}_{t+1}-\varepsilon_{t}+E_{t} \varepsilon_{t+1}\right) \\
\hat{d}_{t}= & \frac{\lambda \bar{\Pi}^{\theta-1}\left(\bar{\Pi}^{1+\theta(1 / \alpha-1)}-1\right)}{1-\lambda \bar{\Pi}^{\theta-1}} \frac{\theta}{\alpha} \hat{\Pi}_{t}+\lambda \bar{\Pi}^{\theta / \alpha} \hat{d}_{t-1}
\end{aligned}
$$


where $\kappa_{h}=\gamma\left(1-\lambda \bar{\Pi}^{\theta-1}\right)\left(1-\beta \lambda \bar{\Pi}^{\theta / \alpha}\right) /\left\{\lambda \bar{\Pi}^{\theta-1}[1+\theta(1 / \alpha-1)]\right\}$ represents the slope of the GNKPC (19). ${ }^{9}$ At a zero rate of trend inflation (i.e., $\bar{\Pi}=1$ ), eq. (20) becomes $\hat{d}_{t}=0$ and thus eq. (19) can be reduced to

$$
\hat{\Pi}_{t}=\beta E_{t} \hat{\Pi}_{t+1}+\kappa_{h, 0} \hat{y}_{t}=\beta E_{t} \hat{\Pi}_{t+1}+\frac{\gamma(1-\lambda)(1-\beta \lambda)}{\lambda[1+\theta(1 / \alpha-1)]} \hat{y}_{t},
$$

which shows that eq. (19) is a GNKPC.

Here three points are particularly worth noting. First, the slope of the GNKPC (13) in the model with firm-specific labor is smaller than that of the GNKPC (19) in the model with homogeneous labor (i.e., $\kappa_{f}<\kappa_{h}$ ), as long as the elasticity of labor supply is finite (i.e., $1 / \eta>0)$. This is an implication of strategic complementarity in price setting incorporated by firm-specific labor for the NKPC, as stressed by previous studies including Bakhshi et al. (2007). Second, in the model with homogeneous labor, the GNKPC (19) depends on price distortion $\hat{d}_{t}$, as long as the trend inflation rate is non-zero (i.e., $\bar{\Pi} \neq 1$ ) and the elasticity of labor supply is finite (i.e., $1 / \eta>0$ ). Then, the persistence of price distortion presented in its law of motion (20) generates endogenously persistent inflation dynamics in that model. Last but not least, in the case of an infinite elasticity of labor supply (i.e., $1 / \eta=0$ ), the GNKPC coincides between the models with firm-specific labor and with homogeneous labor. This implies that in such a case these two models are completely consistent.

\subsection{Calibration}

The ensuing analysis uses a plausible calibration of the model parameters to illustrate conditions for determinacy and for E-stability. The baseline calibration for the quarterly model is summarized in Table 1. In line with Coibion and Gorodnichenko (2011), we set the subjective discount factor at $\beta=0.99$, the elasticity of labor supply at $\eta=1$, the price elasticity of demand for differentiated intermediate goods at $\theta=10$, the labor elasticity of output at $\alpha=1$, and the probability of no price adjustment at $\lambda=0.55 .{ }^{10}$ Then, we have $\gamma=(1+1 / \eta) / \alpha=2$. We also choose the persistence of preference shocks at $\rho=0.35$ similarly to Woodford (2003). Note that to meet Assumption 1 under this calibration, the annualized rate of trend inflation

\footnotetext{
${ }^{9}$ See Appendix B for the derivation of the GNKPC (19).

${ }^{10}$ In Section 5, a robustness exercise that employs the calibration of Ascari and Ropele (2009) (i.e., $\theta=11$, $\lambda=0.75)$ confirms the result obtained with the baseline calibration that the model with firm-specific labor is more susceptible to both indeterminacy and E-instability than the model with homogeneous labor.
} 
needs to be less than 12 percent.

\section{COMPARISON OF EQUILIBRIUM DETERMINACY}

This section compares determinacy of REE between the models with firm-specific and homogeneous labor presented in the preceding section.

\subsection{Equilibrium Determinacy in the Model with Firm-Specific Labor}

We begin with the model with firm-specific labor. In this model, the log-linearized equilibrium conditions (12)-(14) can be reduced to a system of the form

$$
x_{t}=A E_{t} x_{t+1}+B \varepsilon_{t},
$$

where $x_{t}=\left[\hat{\Pi}_{t} \hat{y}_{t} E_{t} \hat{\Pi}_{t+1}\right]^{\prime}$ and the coefficient matrix $A$ is given in Appendix C. ${ }^{11}$

In this system, all variables in $x_{t}$ are non-predetermined, so that the REE is determinate if and only if all eigenvalues of the system's coefficient matrix $A$ are inside the unit circle. We can thus establish the necessary and sufficient condition for determinacy of the REE.

Proposition 1 Suppose that Assumption 1 holds. Then, in the model with firm-specific labor, the REE is determinate if and only if the following two inequalities are satisfied.

$$
\begin{aligned}
& \phi_{\pi}+\phi_{y} \epsilon_{y, f}=\phi_{\pi}+\phi_{y}\left\{\frac{(1-\beta)\left(1-\beta \lambda \bar{\Pi}^{\theta \gamma}\right)}{\kappa_{f}\left(1-\beta \lambda \bar{\Pi}^{\theta-1}\right)}-\frac{\beta \theta \gamma\left(\bar{\Pi}^{1+\theta(\gamma-1)}-1\right)\left(1-\lambda \bar{\Pi}^{\theta-1}\right)}{\kappa_{f}\left(1-\beta \lambda \bar{\Pi}^{\theta-1}\right)[1+\theta(\gamma-1)]}\right\}>1, \\
& {\left[\phi_{y}+\kappa_{f} \phi_{\pi}+1-F^{+}\left(\phi_{y}, \bar{\Pi} ; \beta, \eta, \theta, \alpha, \lambda\right)\right]\left[\phi_{y}+\kappa_{f} \phi_{\pi}+1-F^{-}\left(\phi_{y}, \bar{\Pi} ; \beta, \eta, \theta, \alpha, \lambda\right)\right]>0,}
\end{aligned}
$$

where $F^{ \pm}\left(\phi_{y}, \bar{\Pi} ; \beta, \eta, \theta, \alpha, \lambda\right)=\left(-a_{f} \pm \sqrt{\left(a_{f}\right)^{2}-4 b_{f}}\right) / 2$,

$a_{f}=-\beta\left(1+\lambda \bar{\Pi}^{\theta-1}\left\{\kappa_{f}+\bar{\Pi}^{1+\theta(\gamma-1)}\left[1+\beta\left(1+\phi_{y}\right)\right]-\beta^{2} \lambda \bar{\Pi}^{\theta \gamma}\right\}+\frac{\theta \gamma\left(\bar{\Pi}^{1+\theta(\gamma-1)}-1\right)\left(1-\lambda \bar{\Pi}^{\theta-1}\right)}{1+\theta(\gamma-1)}\right)$,

$b_{f}=\beta^{2} \lambda \bar{\Pi}^{\theta \gamma}\left\{\kappa_{f}+1+\beta\left(1+\phi_{y}\right)-\beta^{2} \lambda \bar{\Pi}^{\theta \gamma}+\frac{\beta\left(\bar{\Pi}^{1+\theta(\gamma-1)}-1\right)\left[\lambda \bar{\Pi}^{\theta-1}+\theta\left(\gamma-\lambda \bar{\Pi}^{\theta-1}\right)\right]\left(1+\phi_{y}\right)}{1+\theta(\gamma-1)}\right\}$.

Proof See Appendix D.1.

The condition (22) can be interpreted as the long-run version of the Taylor principle. The GNKPC (13) implies that each percentage point of permanently higher inflation yields a permanent change in output of $\epsilon_{y, f}$ percentage points, so that $\epsilon_{y, f}$ represents the long-run inflation

\footnotetext{
${ }^{11}$ The form of the coefficient vector $B$ is omitted because it is not needed in what follows.
} 
elasticity of output. Then, $\phi_{\pi}+\phi_{y} \epsilon_{y, f}$ shows the permanent increase in the interest rate by the Taylor rule (14) in response to each unit permanent increase in inflation. The condition (22) thus suggests that in the long run the interest rate should be raised by more than the increase in inflation.

Each panel in the left column of Figure 1 illustrates regions of the Taylor rule's coefficients on inflation and output $\left(\phi_{\pi}, \phi_{y}\right)$ that guarantee determinacy of the REE (as well as E-stability of the fundamental REE analyzed later) at an annualized trend inflation rate of zero, three, and six percent, using the calibration of the model parameters presented in Table 1 . Note that the coefficients estimated by Taylor $(1993)$ are $\left(\phi_{\pi}, \phi_{y}\right)=(1.5,0.5 / 4)=(1.5,0.125)$ - which is marked by " $x$ " in each panel of the figure - and thus it is reasonable to consider the range of $0 \leq \phi_{\pi} \leq 1.5 \times 3=4.5$ and $0 \leq \phi_{y} \leq 0.125 \times 3=0.375$. The left column of the figure demonstrates that higher trend inflation is a more serious source of indeterminacy, in line with Coibion and Gorodnichenko (2011). At a trend inflation rate of three and six percent, the long-run version of the Taylor principle (22) imposes an upper bound on the output coefficient, while the other determinacy condition (23) induces lower bounds on the inflation and output coefficients. These upper and lower bounds become more severe at a higher rate of trend inflation.

The long-run version of the Taylor principle (22) is reduced to the original Taylor principle (i.e., $\phi_{\pi}>1$ ) in the case of no policy response to output, i.e., $\phi_{y}=0$. When the policy response to output is positive (i.e., $\phi_{y}>0$ ), higher trend inflation makes the Taylor principle (22) more restrictive. As trend inflation increases, the long-run inflation elasticity of output $\epsilon_{y, f}$ decreases to become negative and further declines, as the thick line in Figure 2 illustrates using the calibration in Table 1. Then, for a positive value of the Taylor rule's coefficient on output $\phi_{y}$, a lower value of the elasticity $\epsilon_{y, f}$ causes the Taylor principle (22) to be more restrictive. Particularly, once the elasticity $\epsilon_{y, f}$ becomes negative, the implication of the Taylor principle (22) changes dramatically. For a stronger policy response to output, the Taylor principle (22) allows a weaker policy response to inflation under low trend inflation that yields a positive value of the elasticity (i.e., $\epsilon_{y, f}>0$ ), whereas it requires a stronger policy response to inflation under high trend inflation that induces a negative value of the elasticity (i.e., $\epsilon_{y, f}<0$ ). Therefore, at a positive rate of trend inflation higher than the threshold that generates a zero value of the elasticity (i.e., $\epsilon_{y, f}=0$ ), a larger coefficient on output calls for a larger coefficient on inflation in the Taylor rule to satisfy the Taylor principle (22). 
The other determinacy condition (23) consists of two inequalities, one of which can be reduced to $\phi_{y}+\kappa_{f} \phi_{\pi}+1-\beta>0$ at a zero rate of trend inflation (i.e., $\bar{\Pi}=1$ ) and it is the relevant condition for determinacy at a positive rate of trend inflation. In the latter condition, the slope of the GNKPC $(13), \kappa_{f}$, plays a key role. At a zero trend inflation rate, the condition (i.e., $\phi_{y}+\kappa_{f} \phi_{\pi}+1-\beta>0$ ) is satisfied for non-negative values of the Taylor rule's coefficients on inflation and output $\phi_{\pi}, \phi_{y} \geq 0$. As trend inflation increases, the condition is more restrictive for the Taylor rule's coefficients. Higher trend inflation decreases the slope $\kappa_{f}$ of the GNKPC (13). For a positive value of the Taylor rule's coefficient on inflation $\phi_{\pi}$, such a decrease in the slope causes the condition to be more restrictive. Because the slope is positive under Assumption 1, the condition requires a stronger policy response to inflation for a weaker policy response to output at a positive rate of trend inflation. Moreover, in the case of no policy response to output (i.e., $\phi_{y}=0$ ), the condition calls for a stronger policy response to inflation at a higher rate of trend inflation.

In sum, both the determinacy conditions (22) and (23) demonstrate that higher trend inflation is a more serious source of indeterminacy, because it lowers the long-run inflation elasticity of output $\epsilon_{y, f}$ and the GNKPC's slope $\kappa_{f}$.

\subsection{Equilibrium Determinacy in the Model with Homogeneous Labor and Model Comparison}

We turn next to the model with homogeneous labor. In this model, the system of the loglinearized equilibrium conditions (12), (14), (19), and (20) contains one predetermined variable $\hat{d}_{t-1}$ as well as three non-predetermined variables $\hat{\Pi}_{t}, \hat{y}_{t}, E_{t} \hat{\Pi}_{t+1}$, so that an analytical investigation of conditions for determinacy of the REE does not seem generally possible. In the two special cases of a zero trend inflation rate (i.e., $\bar{\Pi}=1$ ) and an infinite elasticity of labor supply (i.e., $1 / \eta=0$ ), the price distortion terms disappear from the GNKPC (19) as noted above, and thus the equilibrium conditions relevant to determinacy of the REE are (12), (14), and (19). Particularly, in the special case of an infinite elasticity of labor supply, these equilibrium conditions are completely consistent with those in the model with firm-specific labor as noted above, and hence there is no difference in equilibrium determinacy between the models with homogeneous labor and with firm-specific labor. Thus, this subsection first focuses on the other special case of a zero trend inflation rate to derive an analytical expression of conditions for de- 
terminacy and compare it with that in the model with firm-specific labor. It then numerically compares equilibrium determinacy at a positive rate of trend inflation between the models with homogeneous versus firm-specific labor.

At a zero rate of trend inflation (i.e., $\bar{\Pi}=1$ ), we can follow Ascari and Ropele (2009) to show that the determinacy conditions are given by

$$
\begin{aligned}
& \phi_{\pi}+\phi_{y} \epsilon_{y, h}=\phi_{\pi}+\phi_{y} \frac{1-\beta}{\kappa_{h}}>1, \\
& \phi_{y}+\kappa_{h} \phi_{\pi}+1-\beta>0 .
\end{aligned}
$$

As in the model with firm-specific labor, the condition (24) can be interpreted as the long-run version of the Taylor principle, and it is reduced to the original Taylor principle (i.e., $\phi_{\pi}>1$ ) in the case of no policy response to output, i.e., $\phi_{y}=0$. In addition, the other condition (25) is satisfied for non-negative values of the Taylor rule's coefficients on inflation and output, $\phi_{\pi}, \phi_{y} \geq 0$. In the latter condition, the GNKPC's slope $\kappa_{h}$ plays a role. As discussed by Ascari and Ropele (2009), if a negative value of the output coefficient is allowed (i.e., $\phi_{y}<0$ ), for a positive value of the inflation coefficient $\phi_{\pi}$ a smaller value of the slope $\kappa_{h}$ causes the condition (25) to be more restrictive.

In the model with firm-specific labor, Proposition 1 implies that at a zero rate of trend inflation (i.e., $\bar{\Pi}=1$ ), the determinacy conditions are given by

$$
\begin{aligned}
& \phi_{\pi}+\phi_{y} \epsilon_{y, f}=\phi_{\pi}+\phi_{y} \frac{1-\beta}{\kappa_{f}}>1, \\
& \phi_{y}+\kappa_{f} \phi_{\pi}+1-\beta>0 .
\end{aligned}
$$

Because $\kappa_{f} \leq \kappa_{h}$ and hence it follows that $\epsilon_{y, f} \geq \epsilon_{y, h}$ at a zero rate of trend inflation, the determinacy condition (24) in the model with homogeneous labor is more restrictive for the Taylor rule's coefficients than its counterpart (26) in the model with firm-specific labor, while the other determinacy condition (25) is less restrictive than its counterpart (27), although these two conditions (25) and (27) are satisfied for non-negative values of the Taylor rule's coefficients on inflation and output. Consequently, for non-negative values of the coefficients, equilibrium determinacy is more prevalent in the model with firm-specific labor than in the model with homogeneous labor. However, this is the case only when the trend inflation rate is lower than a certain threshold that is positive but close to zero (e.g., 0.2 percent in annualized rate terms under the calibration presented in Table 1). 
Once the trend inflation rate exceeds the threshold, the model with firm-specific labor is more susceptible to indeterminacy of equilibrium than the model with homogeneous labor. When the annualized trend inflation rate is three and six percent, the two lower panels in the right column of Figure 1 illustrate regions of the Taylor rule's coefficients on inflation and output $\left(\phi_{\pi}, \phi_{y}\right)$ that guarantee determinacy of the REE (as well as E-stability of the fundamental REE analyzed later) in the model with homogeneous labor, using the calibration in Table 1 . These panels show that at a trend inflation rate of three and six percent, determinacy of the REE in the model with homogeneous labor is ensured as long as the Taylor rule's coefficients satisfy the long-run version of the Taylor principle

$$
\phi_{\pi}+\phi_{y} \epsilon_{y, h}>1
$$

where the long-run inflation elasticity of output $\epsilon_{y, h}$ is generalized as

$\epsilon_{y, h}=\frac{(1-\beta)\left(1-\beta \lambda \bar{\Pi}^{\theta / \alpha}\right)}{\kappa_{h}\left(1-\beta \lambda \bar{\Pi}^{\theta-1}\right)}-\frac{\beta \theta / \alpha\left(\bar{\Pi}^{1+\theta(1 / \alpha-1)}-1\right)\left(1-\lambda \bar{\Pi}^{\theta-1}\right)}{\kappa_{h}\left(1-\beta \lambda \bar{\Pi}^{\theta-1}\right)[1+\theta(1 / \alpha-1)]}-\frac{\theta / \alpha\left(\bar{\Pi}^{1+\theta(1 / \alpha-1)}-1\right) \lambda \bar{\Pi}^{\theta-1}}{\eta \gamma\left(1-\lambda \bar{\Pi}^{\theta-1}\right)\left(1-\lambda \bar{\Pi}^{\theta / \alpha}\right)}$.

The comparison of the left and right columns of Figure 1 demonstrates that the model with firm-specific labor is more susceptible to indeterminacy of equilibrium than the model with homogeneous labor when the trend inflation rate is three and six percent, both of which are higher than the threshold. This is because both the long-run version of the Taylor principle and the other determinacy condition are more restrictive when labor is firm-specific than when it is homogeneous. The long-run version of the Taylor principle is more restrictive when the long-run inflation elasticity of output is smaller. At a trend inflation rate that is higher than the threshold, strategic complementarity in price setting incorporated by firm-specific labor causes the elasticity in this model to be lower than that in the model with homogeneous labor, as illustrated in Figure 2, and thereby makes the long-run version of the Taylor principle more restrictive in the former model than in the latter. Then, if the policy response to output is strong, a policy response to inflation that ensures determinacy in the model with homogeneous labor can induce indeterminacy in the model with firm-specific labor. The other determinacy condition is more restrictive when the slope of the GNKPC is smaller. Because the strategic complementarity causes the slope in the model with firm-specific labor to be lower than that in the model with homogeneous labor as noted above, the region of the Taylor rule's coefficients that satisfy this condition in the former model is smaller than that in the latter. Then, if the policy response to output is weak, a policy response to inflation that ensures determinacy in 
the model with homogeneous labor can induce indeterminacy in the model with firm-specific labor.

The argument above has demonstrated that indeterminacy caused by high trend inflation is more prevalent when labor is firm-specific than when it is homogeneous. Accordingly, the argument of Coibion and Gorodnichenko (2011) - a decline in trend inflation, along with an increase in the Federal Reserves's policy response to inflation, accounts for much of the U.S. economy's shift from indeterminacy in the Great Inflation era to determinacy in the Great Moderation era - could depend crucially on their assumption of firm-specific labor. Under the calibration of the model parameters presented in Table 1, which is also chosen by Coibion and Gorodnichenko, the model with homogeneous labor argues for Clarida et al. (2000) and Lubik and Schorfheide (2004), who all attribute the U.S. economy's shift solely to the Federal Reserve's switch from a passive to an active policy response to inflation.

\section{COMPARISON OF EXPECTATIONAL STABILITY}

This section compares E-stability of fundamental REE between the models with firm-specific and homogeneous labor.

\subsection{E-Stability in the Model with Firm-Specific Labor}

This subsection examines E-stability of the fundamental REE in the model with firm-specific labor. Following the literature on learning in macroeconomics (e.g., Bullard and Mitra, 2002; Evans and Honkapohja, 2001), the present paper uses the so-called "Euler equation" approach suggested by Honkapohja et al. (2011). That is, the rational expectation operator $E_{t}$ is replaced with a possibly non-rational expectation operator $\hat{E}_{t}$ in the equilibrium conditions (12)-(14). The resulting conditions can be reduced to a system of the form

$$
z_{t}=C \hat{E}_{t} z_{t+1}+D[10] \hat{E}_{t} z_{t+2}+F \varepsilon_{t}
$$

where $z_{t}=\left[\hat{\Pi}_{t} \hat{y}_{t}\right]^{\prime}$ and the coefficient matrix $C$ and vector $D$ are given in Appendix C. ${ }^{12}$ By the method of undetermined coefficients, it follows that the fundamental REE in this system can be given by

$$
z_{t}=\bar{c}+\bar{\Gamma} \varepsilon_{t}=0_{2 \times 1}+\left(I-\rho C-\rho^{2} D[10]\right)^{-1} F \varepsilon_{t},
$$

\footnotetext{
${ }^{12}$ The form of the coefficient vector $F$ is omitted because it is not needed in what follows.
} 
where $I$ denotes a conformable identity matrix. ${ }^{13}$

Following Section 10.3 of Evans and Honkapohja (2001), we investigate E-stability of the fundamental REE (30). Corresponding to this REE, all agents are assumed to be endowed with a perceived law of motion (PLM) of $z_{t}$

$$
z_{t}=c+\Gamma \varepsilon_{t} .
$$

Using forecasts from this PLM to substitute $\hat{E}_{t} z_{t+1}$ and $\hat{E}_{t} z_{t+2}$ out of the system (29) leads to the actual law of motion (ALM) of $z_{t}$

$$
z_{t}=\left(C+D\left[\begin{array}{ll}
1 & 0
\end{array}\right]\right) c+\left[\rho\left(C+\rho D\left[\begin{array}{ll}
1 & 0
\end{array}\right]\right) \Gamma+F\right] \varepsilon_{t} .
$$

Then, the mapping $T$ from the PLM (31) to the ALM (32) can be defined by $T(c, \Gamma)=$ $\left(\left(C+D\left[\begin{array}{ll}1 & 0\end{array}\right]\right) c, \rho(C+\rho D[1 \quad 0]) \Gamma+F\right)$. For the fundamental REE $(\bar{c}, \bar{\Gamma})$ to be E-stable, the matrix differential equation $\frac{d}{d \tau}\left(c, \Gamma_{z}\right)=T(c, \Gamma)-(c, \Gamma)$ must have local asymptotic stability at the REE, where $\tau$ denotes a notional time. Hence, the fundamental REE $(\bar{c}, \bar{\Gamma})$ is E-stable if and only if all eigenvalues of two matrices, $D T_{c}(\bar{c}, \bar{\Gamma})=C+D\left[\begin{array}{ll}1 & 0\end{array}\right]$ and $D T_{\Gamma}(\bar{c}, \bar{\Gamma})=\rho\left(C+\rho D\left[\begin{array}{ll}1 & 0\end{array}\right)\right.$, have real parts less than unity. We can thus establish the necessary and sufficient condition for E-stability of the fundamental REE.

Proposition 2 Suppose that Assumption 1 holds. Then, in the model with firm-specific labor, the fundamental REE is E-stable if and only if the long-run version of the Taylor principle (22) and the following two inequalities are satisfied.

$$
\left[2-\beta-\beta \lambda \bar{\Pi}^{\theta \gamma}(1-\beta)-\frac{\beta \theta \gamma\left(\bar{\Pi}^{1+\theta(\gamma-1)}-1\right)\left(1-\lambda \bar{\Pi}^{\theta-1}\right)}{1+\theta(\gamma-1)}\right]\left(\phi_{y}+1\right)+\kappa_{f}\left(2-\beta \lambda \bar{\Pi}^{\theta-1}\right) \phi_{\pi}>1+\kappa_{f},
$$

$\phi_{\pi}+\left\{\frac{(1-\rho \beta)\left(1-\rho \beta \lambda \bar{\Pi}^{\theta \gamma}\right)}{\kappa_{f}\left(1-\rho \beta \lambda \bar{\Pi}^{\theta-1}\right)}-\frac{\rho \beta \theta \gamma\left(\bar{\Pi}^{1+\theta(\gamma-1)}-1\right)\left(1-\lambda \bar{\Pi}^{\theta-1}\right)}{\kappa_{f}\left(1-\rho \beta \lambda \bar{\Pi}^{\theta-1}\right)[1+\theta(\gamma-1)]}\right\}\left(\phi_{y}+1-\rho\right)>\rho$.

Proof See Appendix D.2.

This proposition shows that the long-run version of the Taylor principle (22) is also a necessary condition for E-stability in the model with firm-specific labor.

\footnotetext{
${ }^{13}$ The persistence parameter of the preference shock, $\rho$, affects the fundamental REE through the expectations in the system (29).
} 
Each panel in the left column of Figure 1 illustrates regions of the Taylor rule's coefficients on inflation and output $\left(\phi_{\pi}, \phi_{y}\right)$ that guarantee E-stability of the fundamental REE, in addition to determinacy of the REE. It demonstrates that higher trend inflation is a more serious source of E-instability as well as indeterminacy. Moreover, indeterminacy is more prevalent than Einstability, especially when the output coefficient $\phi_{y}$ is small. As in the analysis of equilibrium determinacy, at an annualized trend inflation rate of three and six percent, the Taylor principle (22) imposes an upper bound on the output coefficient, while the E-stability condition (33) induces lower bounds on the inflation and output coefficients, as is similar to the determinacy condition (23). These upper and lower bounds become more severe at a higher rate of trend inflation. The remaining E-stability condition (34) does not appear in the figure.

The E-stability condition (33) acts in a similar manner to the determinacy condition (23). The former condition is satisfied for non-negative values of the Taylor rule's coefficients on inflation and output $\phi_{\pi}, \phi_{y} \geq 0$ at a zero rate of trend inflation (i.e., $\bar{\Pi}=1$ ), where this condition is implied by the Taylor principle (22) in line with Bullard and Mitra (2002). As trend inflation increases, the condition (33) becomes more restrictive. In this condition, the slope of the GNKPC (13), $\kappa_{f}$, plays a role. A lower value of the slope causes the condition to be more restrictive. These properties of the condition still hold even in the case of no policy response to output, i.e., $\phi_{y}=0$.

In the remaining E-stability condition (34), the persistence of the shock, $\rho$, plays a crucial role. When the shock is i.i.d. (i.e., $\rho=0$ ), this condition is satisfied for non-negative values of the Taylor rule's coefficients on inflation and output $\phi_{\pi}, \phi_{y} \geq 0$ at any rate of trend inflation. As the shock persistence $\rho$ increases, the condition becomes more restrictive. This restrictiveness becomes more severe with higher trend inflation, regardless of whether the Taylor rule's coefficient on output $\phi_{y}$ is zero or positive.

In sum, as with the indeterminacy result, the E-stability conditions (22), (33), and (34) demonstrate that higher trend inflation is a more serious source of E-instability, because it reduces the long-run inflation elasticity of output $\epsilon_{y, f}$ and the GNKPC's slope $\kappa_{f}$. 


\subsection{E-Stability in the Model with Homogeneous Labor and Model Compar- ison}

In the model with homogeneous labor, an analytical investigation of conditions for E-stability of the fundamental REE does not seem generally possible, as with the analysis of equilibrium determinacy. Thus, this subsection also begins by focusing on the special case of a zero trend inflation rate to derive an analytical expression of E-stability conditions and compare it with that in the model with firm-specific labor. It then numerically compares E-stability at a positive rate of trend inflation between the models with homogeneous and firm-specific labor. ${ }^{14}$

When the trend inflation rate is zero (i.e., $\bar{\Pi}=1$ ), it can be shown that in the model with homogeneous labor, the long-run version of the Taylor principle (24) is the only E-stability condition (for non-negative values of the Taylor rule's coefficients on inflation and output $\left.\phi_{\pi}, \phi_{y} \geq 0\right)$. Moreover, in the model with firm-specific labor, Proposition 2 implies that the long-run version of the Taylor principle (26) is the only E-stability condition. Therefore, as with the indeterminacy result, E-stability of fundamental REE is more prevalent in the model with firm-specific labor than in the model with homogeneous labor, as long as the rate of trend inflation is smaller than the threshold mentioned above.

Once the trend inflation rate exceeds the threshold, the model with firm-specific labor is more susceptible to E-instability than the model with homogeneous labor. Each panel in the right column of Figure 1 illustrates regions of the Taylor rule's coefficients on inflation and output $\left(\phi_{\pi}, \phi_{y}\right)$ that guarantee E-stability, in addition to determinacy, in the model with homogeneous labor. The comparison of the left and right columns of Figure 1 demonstrates that at an annualized trend inflation rate of three and six percent, the model with firm-specific labor is more susceptible to E-instability than the model with homogeneous labor. This E-instability result arises for two reasons. First, the long-run version of the Taylor principle (i.e., (22)) is

\footnotetext{
${ }^{14}$ To analyze E-stability of the fundamental REE in the model with homogeneous labor, we follow Section 10.5 of Evans and Honkapohja (2001). The system of the equilibrium conditions (12), (14), (19), and (20) contains the predetermined variable $\hat{d}_{t-1}$ and thus it is possible to consider two learning environments, which are studied respectively in Sections 10.3 and 10.5 of Evans and Honkapohja (2001). One environment allows agents to use current endogenous variables in expectation formation, whereas the other does not. Here we show only E-stability analysis under the latter environment as in Bullard and Mitra (2002), Kurozumi (2006, 2014), and Kurozumi and Van Zandweghe $(2008,2012)$. This is because the former induces a problem with the simultaneous determination of expectations and current endogenous variables, which is critical to equilibrium under non-rational expectations as indicated by Evans and Honkapohja (2001) and Bullard and Mitra (2002).
} 
a necessary condition for E-stability of the fundamental REE in the model with firm-specific labor, as shown in Proposition 2, whereas its counterpart in the model with homogeneous labor (i.e., (28)) must not always be met. ${ }^{15}$ Moreover, the Taylor principle (22) in the former model is more restrictive than the Taylor principle (28) in the latter model as noted above, and thus E-instability is more prevalent in the model with firm-specific labor. Second, when labor is homogeneous, price distortion appears in the GNKPC (19) and the persistence presented in its law of motion (20) generates endogenously persistent inflation dynamics, as long as the trend inflation rate is non-zero and the elasticity of labor supply is finite. For the REE in question, E-stability examines whether an associated equilibrium in which agents form expectations under adaptive learning reaches over time that REE. Under such expectation formation, the endogenous persistence of inflation dynamics through the law of motion of price distortion (i.e., the presence of lagged price distortion in agents' PLM as a model state variable relevant to their learning) helps agents form inflation expectations and learn the fundamental REE in the model with homogeneous labor. By contrast, this is not the case in the model with firm-specific labor. Price distortion and hence its induced endogenous persistence is absent in the GNKPC (13), and thus higher trend inflation is a more serious source of E-instability. Therefore, Einstability caused by high trend inflation is more prevalent when labor is firm-specific than when it is homogeneous.

\section{ROBUSTNESS EXERCISES}

This section checks the robustness of the indeterminacy and E-instability results presented above in terms of the specification of monetary policy rules and the calibration of the model parameters.

\subsection{On Specification of Monetary Policy Rules}

To examine the robustness of the indeterminacy and E-instability results obtained with the Taylor rule (14), we use three modifications of the rule: (i) a forecast-based specification of the Taylor rule, (ii) the Taylor rule with policy rate smoothing, and (iii) the Taylor rule with

\footnotetext{
${ }^{15}$ In Section 5, a robustness exercise using the calibration of Ascari and Ropele (2009) (i.e., $\theta=11, \lambda=0.75$ ) demonstrates that the long-run version of the Taylor principle (28) is not a necessary condition for E-stability of the fundamental REE at an annualized trend inflation rate of six percent.
} 
responses to output growth.

\subsubsection{Forecast-based Taylor rule}

We begin with a forecast-based specification of the Taylor rule. This adjusts the policy rate $R_{t}$ in response to deviations of inflation and output forecasts, $E_{t} \Pi_{t+1}$ and $E_{t} Y_{t+1}$, from their trend levels

$$
\hat{R}_{t}=\phi_{\pi} E_{t} \hat{\Pi}_{t+1}+\phi_{y} E_{t} \hat{y}_{t+1}
$$

In the model with firm-specific labor, the log-linearized equilibrium conditions are given by (12), (13), and (35). Thus, as is similar to the case of the benchmark Taylor rule (14), we can establish the necessary and sufficient conditions under which the forecast-based Taylor rule (35) guarantees determinacy of the REE and E-stability of the fundamental REE.

Proposition 3 Suppose that Assumption 1 holds. Then, in the model with firm-specific labor and the forecast-based Taylor rule (35), the REE is determinate if and only if the long-run version of the Taylor principle (22) and the following two inequalities are satisfied.

$$
\begin{aligned}
& \phi_{\pi}+\frac{(1+\beta)\left(1+\beta \lambda \bar{\Pi}^{\theta \gamma}\right)[1+\theta(\gamma-1)]+\beta \theta \gamma\left(\bar{\Pi}^{1+\theta(\gamma-1)}-1\right)\left(1-\lambda \bar{\Pi}^{\theta-1}\right)}{\kappa_{f}\left(1+\beta \lambda \bar{\Pi}^{\theta-1}\right)[1+\theta(\gamma-1)]}\left(\phi_{y}-2\right)<1, \\
& {\left[\phi_{y}-1-G_{f}^{+}\left(\phi_{\pi}, \bar{\Pi} ; \beta, \eta, \theta, \alpha, \lambda\right)\right]\left[\phi_{y}-1-G_{f}^{-}\left(\phi_{\pi}, \bar{\Pi} ; \beta, \eta, \theta, \alpha, \lambda\right)\right]>0,}
\end{aligned}
$$

where $G_{f}^{ \pm}\left(\phi_{\pi}, \bar{\Pi} ; \beta, \eta, \theta, \alpha, \lambda\right)=\left(-c_{f} \pm \sqrt{\left(c_{f}\right)^{2}-4 d_{f} e_{f}}\right) /\left(2 d_{f}\right)$,

$$
\begin{aligned}
& c_{f}=\beta\left\{\left(1-\beta^{2} \lambda \bar{\Pi}^{\theta \gamma}\right)\left[1+\lambda \bar{\Pi}^{\theta \gamma}+\frac{\theta \gamma\left(\bar{\Pi}^{1+\theta(\gamma-1)}-1\right)\left(1-\lambda \bar{\Pi}^{\theta-1}\right)}{1+\theta(\gamma-1)}\right]+\kappa_{f} \beta \lambda \bar{\Pi}^{\theta \gamma}\left(\phi_{\pi}-1\right)\right\}, \\
& d_{f}=\beta^{2} \lambda \bar{\Pi}^{\theta \gamma}\left(1-\beta^{2} \lambda \bar{\Pi}^{\theta \gamma}\right), \quad e_{f}=1-\beta \lambda\left[\beta \bar{\Pi}^{\theta \gamma}-\kappa_{f} \bar{\Pi}^{\theta-1}\left(\phi_{\pi}-1\right)\right] .
\end{aligned}
$$

Proof See Appendix D.3.

Proposition 4 Suppose that Assumption 1 holds. Then, in the model with firm-specific labor and the forecast-based Taylor rule (35), the fundamental REE is E-stable if and only if the long-run version of the Taylor principle (22) and the following two inequalities are satisfied.

$$
\begin{aligned}
& \phi_{y}+\kappa_{f} \phi_{\pi}>\kappa_{f}-(1-\beta)\left(1-\beta \lambda \bar{\Pi}^{\theta \gamma}\right)+\frac{\beta \theta \gamma\left(\bar{\Pi}^{1+\theta(\gamma-1)}-1\right)\left(1-\lambda \bar{\Pi}^{\theta-1}\right)}{1+\theta(\gamma-1)} \\
& \rho\left(\phi_{\pi}-1\right)+\left\{\frac{(1-\rho \beta)\left(1-\rho \beta \lambda \bar{\Pi}^{\theta \gamma}\right)}{\kappa_{f}\left(1-\rho \beta \lambda \bar{\Pi}^{\theta-1}\right)}-\frac{\rho \beta \theta \gamma\left(\bar{\Pi}^{1+\theta(\gamma-1)}-1\right)\left(1-\lambda \bar{\Pi}^{\theta-1}\right)}{\kappa_{f}\left(1-\rho \beta \lambda \bar{\Pi}^{\theta-1}\right)[1+\theta(\gamma-1)]}\right\}\left(\rho \phi_{y}+1-\rho\right)>0 .
\end{aligned}
$$

Proof See Appendix D.4. 
These propositions yield each panel in the left column of Figure 3, which illustrates regions of the inflation and output coefficients $\left(\phi_{\pi}, \phi_{y}\right)$ of the forecast-based Taylor rule (35) that ensure determinacy of the REE and E-stability of the fundamental REE, using the calibration presented in Table 1. Note that the long-run version of the Taylor principle for the forecastbased Taylor rule (35) is the same as the one (22) for the benchmark Taylor rule (14), because in the long run there is no difference between these two rules. At an annualized trend inflation rate of three and six percent, the Taylor principle (22) imposes an upper bound on the output coefficient, while the determinacy condition (37) and the E-stability condition (38) induce lower bounds on the inflation and output coefficients, as is similar to the determinacy condition (23) and the E-stability condition (33) in the case of the benchmark Taylor rule (14). These upper and lower bounds become more severe at a higher rate of trend inflation. The remaining determinacy condition (36) and E-stability condition (39) do not appear in the figure. The lower bounds on the inflation and output coefficients of the forecast-based Taylor rule (35) are more restrictive than those of the benchmark Taylor rule (14) shown in the left column of Figure 1. Consequently, both the regions of indeterminacy and of E-instability are larger in the case of the forecast-based Taylor rule (35).

In the model with homogeneous labor, an analytical investigation of conditions for determinacy and for E-stability does not seem generally possible, as in the case of the benchmark Taylor rule (14). Thus, a numerical investigation is conducted. Each panel in the right column of Figure 3 illustrates regions of the inflation and output coefficients $\left(\phi_{\pi}, \phi_{y}\right)$ of the forecastbased Taylor rule (35) that ensure determinacy and E-stability in the model with homogeneous labor, using the calibration in Table 1 . As is the case with the model with firm-specific labor, the long-run version of the Taylor principle for the forecast-based Taylor rule (35) is the same as the one (28) for the benchmark Taylor rule (14), and the Taylor principle (28) generates an upper bound on the output coefficient guaranteeing determinacy and E-stability at an annualized trend inflation rate of three and six percent. In addition, there emerge lower bounds on the inflation and output coefficients ensuring determinacy and E-stability, which do not appear in the right column of Figure 1 for the benchmark Taylor rule (14). This implies that both the regions of indeterminacy and of E-instability are larger in the case of the forecast-based Taylor rule (35) than in the case of the benchmark Taylor rule (14).

The comparison of the left and right columns of Figure 3 confirms the result obtained with the benchmark Taylor rule (14) that indeterminacy and E-instability caused by high trend 
inflation are more prevalent in the model with firm-specific labor than in the model with homogeneous labor.

\subsubsection{Taylor rule with policy rate smoothing}

We turn next to the Taylor rule with policy rate smoothing. This rule introduces a partial adjustment of the policy rate in the Taylor rule (14). Specifically, it takes the form

$$
\hat{R}_{t}=\rho_{r} \hat{R}_{t-1}+\left(1-\rho_{r}\right)\left(\phi_{\pi} \hat{\Pi}_{t}+\phi_{y} \hat{y}_{t}\right),
$$

where $\rho_{r} \in[0,1)$ represents the degree of policy rate smoothing. Because the rule adds the lagged policy rate $\hat{R}_{t-1}$ to the set of predetermined variables in both the models with firmspecific labor and with homogeneous labor, an analytical investigation of conditions for determinacy of REE and for E-stability of fundamental REE does not seem generally possible in these two models. This subsection thus numerically compares determinacy and E-stability between the two models. To this end the degree of policy rate smoothing is set at $\rho_{r}=0.86$. This value is the same as the estimate by Coibion and Gorodnichenko (2011) for their preferred specification of the Taylor rule (the "mixed Taylor rule") during the post-1982 period. ${ }^{16}$

In the model with firm-specific labor, each panel in the left column of Figure 4 illustrates regions of the inflation and output coefficients $\left(\phi_{\pi}, \phi_{y}\right)$ of the Taylor rule with policy rate smoothing (40) that ensure determinacy of the REE and E-stability of the fundamental REE, using the calibration presented in Table 1. One point to be emphasized here is that the longrun version of the Taylor principle for the Taylor rule with policy rate smoothing (40) is the same as the one (22) for the benchmark Taylor rule (14), implying that the partial adjustment of the policy rate never alters the form of the long-run version of the Taylor principle. This is also true in the model with homogeneous labor. That is, the long-run version of the Taylor principle for the rule (40) is the same as the one (28) for the benchmark rule (14).

As emphasized by Coibion and Gorodnichenko (2011), policy rate smoothing helps the Taylor rule ensure determinacy in the model with firm-specific labor when the trend inflation rate is positive. The region of indeterminacy at an annualized trend inflation rate of three and six percent in the left column of Figure 4 is smaller than its counterpart in Figure 1 . The smoothing also supports the Taylor rule in guaranteeing E-stability in the case of a positive

\footnotetext{
${ }^{16}$ The mixed Taylor rule adjusts the policy rate in response to the past policy rates, the forecast of future inflation, the output gap, and output growth.
} 
rate of trend inflation. The region of E-instability at a trend inflation rate of three and six percent in the left column of Figure 4 is smaller than its counterpart in Figure 1.

In the model with homogeneous labor, each panel in the right column of Figure 4 illustrates regions of the inflation and output coefficients $\left(\phi_{\pi}, \phi_{y}\right)$ of the Taylor rule with policy rate smoothing (40) that ensure determinacy and E-stability, using the calibration in Table 1. These regions are identical to their counterparts in Figure 1. In each panel the long-run version of the Taylor principle (28) is the only relevant condition for both determinacy and E-stability. The comparison of the left and right columns of Figure 4 confirms the indeterminacy and E-instability results obtained with the benchmark Taylor rule (14).

\subsubsection{Taylor rule with responses to output growth}

Last, we analyze the Taylor rule with responses to output growth. This rule incorporates a policy response to output growth in the Taylor rule (14). Specifically, it takes the form

$$
\hat{R}_{t}=\phi_{\pi} \hat{\Pi}_{t}+\phi_{y} \hat{y}_{t}+\phi_{d y}\left(\hat{y}_{t}-\hat{y}_{t-1}\right),
$$

where $\phi_{d y} \geq 0$ represents the degree of the policy response to output growth. As this rule adds lagged output $\hat{y}_{t-1}$ to the set of predetermined variables in both the models with firm-specific labor and with homogeneous labor, an analytical investigation of conditions for determinacy and for E-stability does not seem generally possible. This subsection thus numerically compares determinacy and E-stability between the models with firm-specific versus homogeneous labor. To this end the degree of the policy response to output growth is set at $\phi_{d y}=1.56$. This value is the same as the estimate by Coibion and Gorodnichenko (2011) for their preferred specification of the Taylor rule during the post-1982 period.

In the model with firm-specific labor, each panel in the left column of Figure 5 illustrates regions of the inflation and output coefficients $\left(\phi_{\pi}, \phi_{y}\right)$ of the Taylor rule with responses to output growth (41) that ensure determinacy of the REE and E-stability of the fundamental REE, using the calibration presented in Table 1. In the long run there is no difference between the Taylor rules with and without responses to output growth (i.e., (14) and (41)) because any permanent increase in output induces no change in output growth. Consequently, these two rules lead to the same long-run version of the Taylor principle (22). This is also true in the model with homogeneous labor, i.e., the long-run version of the Taylor principle for the rule (41) is the same as the one (28) for the benchmark rule (14). 
As stressed by Coibion and Gorodnichenko (2011), policy responses to output growth greatly help the Taylor rule ensure determinacy in the model with firm-specific labor when the trend inflation rate is positive. The region of indeterminacy at an annualized trend inflation rate of three and six percent in the left column of Figure 5 is smaller than its counterpart in Figure 1. Moreover, at each trend inflation rate of zero, three, and six percent, the long-run version of the Taylor principle (22) is the only relevant condition for determinacy, in contrast to the case of the benchmark Taylor rule (14). This also holds for E-stability. The Taylor principle (22) is the only relevant condition for E-stability at a trend inflation rate of zero, three, and six percent. The region of E-instability at the rate of three and six percent (in the left column of Figure 5) is smaller than its counterpart in Figure 1. Hence, policy responses to output growth also support the Taylor rule to guarantee E-stability in the case of a positive rate of trend inflation.

In the model with homogeneous labor, the regions regarding determinacy and E-stability in the right column of Figure 5 are identical to their counterparts in Figure 1. At each trend inflation rate of zero, three, and six percent, the long-run version of the Taylor principle (28) is the only relevant condition for both determinacy and E-stability. The comparison of the left and right columns of Figure 5 confirms the indeterminacy and E-instability results obtained with the benchmark Taylor rule (14). ${ }^{17}$

\subsection{On Calibration of Model Parameters}

This subsection examines the robustness of the indeterminacy and E-instability results obtained under the baseline calibration of the model parameters presented in Table 1, which is based on Coibion and Gorodnichenko (2011). Specifically, the calibration of Ascari and Ropele (2009) is employed here. In the latter calibration, the price elasticity of demand for differentiated intermediate goods and the probability of no price adjustment are set respectively at $\theta=11$ and $\lambda=0.75$, while maintaining the values of the other model parameters in Table 1.

Under the alternative calibration, each panel in the left column of Figure 6 illustrates regions of the inflation and output coefficients $\left(\phi_{\pi}, \phi_{y}\right)$ of the Taylor rule (14) that ensure

\footnotetext{
${ }^{17}$ The same results are obtained with a more general Taylor rule that includes both the response to output growth and policy rate smoothing. For $\rho_{r}=0.86$ and $\phi_{\pi}=1.56$, the regions of the Taylor rule's coefficients on inflation and output that ensure determinacy of the REE and E-stability of the fundamental REE are identical to those displayed in Figure 5.
} 
determinacy of the REE and E-stability of the fundamental REE in the model with firmspecific labor. Compared with its counterpart in Figure 1 under the baseline calibration, each panel in the left column of Figure 6 shows that indeterminacy and E-instability caused by high trend inflation is more prevalent under the alternative calibration. This arises mainly from the increase in the probability of no price adjustment from $\lambda=0.55$ to $\lambda=0.75$, which in turn lowers both the long-run inflation elasticity of output and the slope of the GNKPC. The same is true in the model with homogeneous labor. In this model, each panel in the right column of Figure 6 illustrates regions of the inflation and output coefficients $\left(\phi_{\pi}, \phi_{y}\right)$ of the Taylor rule (14) that ensure determinacy and E-stability under the alternative calibration. One point to be stressed here is that at an annualized trend inflation rate of six percent the long-run version of the Taylor principle (28) is no longer a necessary condition for E-stability in the model with homogeneous labor. The comparison of the left and right columns of Figure 6 confirms the indeterminacy and E-instability results obtained under the baseline calibration.

\section{CONCLUDING REMARKS}

This paper has compared implications of a non-zero rate of trend inflation for determinacy of REE and E-stability of fundamental REE under the Taylor rule between Calvo sticky price models with firm-specific and homogeneous labor. The two different specifications of labor lead to distinct representations of inflation dynamics, which brings about two main results. First, the model with firm-specific labor is more susceptible to indeterminacy of REE induced by high trend inflation than the model with homogeneous labor. Second, the former model is more susceptible to E-instability of fundamental REE. Accordingly, the argument of Coibion and Gorodnichenko (2011) - a decline in trend inflation, along with an increase in the Federal Reserve's policy response to inflation, explains much of the U.S. economy's shift from indeterminacy in the Great Inflation era to determinacy in the Great Moderation era-could depend crucially on their assumption of firm-specific labor. Thus, future work will estimate the models with firm-specific labor and with homogeneous labor using the method of Lubik and Schorfheide (2004) to empirically address the question of whether a decline in trend inflation is a source of the U.S. economy's shift. 


\section{APPENDIX}

\section{A EQUILIBRIUM CONDITIONS AND STEADY STATE}

This appendix presents equilibrium conditions and the steady state of the models with firmspecific labor and with homogeneous labor in terms of stationary variables.

In the model with firm-specific labor, the four equilibrium conditions for the four stationary variables - inflation $\Pi_{t}$, the relative price $b_{t}=B_{t} / P_{t}$, detrended output $y_{t}=Y_{t} / A_{t}$, and the interest rate $R_{t}$-are given by

$$
\begin{aligned}
1 & =E_{t}\left(\frac{\beta}{\exp (g)} \frac{y_{t} \exp \left(\varepsilon_{t+1}\right)}{y_{t+1} \exp \left(\varepsilon_{t}\right)} \frac{R_{t}}{\Pi_{t+1}}\right), \\
0 & =E_{t} \sum_{j=0}^{\infty}(\beta \lambda)^{j} \exp \left(\varepsilon_{t+j}\right)\left[\left(b_{t} \prod_{k=1}^{j} \frac{1}{\Pi_{t+k}}\right)^{1-\theta}-\frac{\theta}{\alpha(\theta-1)} y_{t+j}^{\gamma}\left(b_{t} \prod_{k=1}^{j} \frac{1}{\Pi_{t+k}}\right)^{-\theta \gamma}\right], \\
1 & =(1-\lambda) b_{t}^{1-\theta}+\lambda \Pi_{t}^{\theta-1}, \\
\ln R_{t} & =\ln R+\phi_{\pi}\left(\ln E_{t} \Pi_{t+i}-\ln \bar{\Pi}\right)+\phi_{y}\left(\ln E_{t} y_{t+i}-\ln y\right), \quad i=0,1,
\end{aligned}
$$

and the steady state with trend inflation $\bar{\Pi}$ is given by

$$
R=\frac{\bar{\Pi} \exp (g)}{\beta}, \quad b=\left(\frac{1-\lambda \bar{\Pi}^{\theta-1}}{1-\lambda}\right)^{1 /(1-\theta)}, \quad y=\left[\frac{\alpha(\theta-1)}{\theta} \frac{1-\beta \lambda \bar{\Pi}^{\theta \gamma}}{1-\beta \lambda \bar{\Pi}^{\theta-1}} b^{1+\theta(\gamma-1)}\right]^{1 / \gamma} .
$$

In the model with homogeneous labor, the five equilibrium conditions for the five stationary variables - inflation $\Pi_{t}$, the relative price $b_{t}=B_{t} / P_{t}$, price distortion $d_{t}$, detrended output $y_{t}=Y_{t} / A_{t}$, and the interest rate $R_{t}$-are given by eqs. (42), (44), (45), and

$$
\begin{aligned}
0 & =E_{t} \sum_{j=0}^{\infty}(\beta \lambda)^{j} \exp \left(\varepsilon_{t+j}\right)\left[\left(b_{t} \prod_{k=1}^{j} \frac{1}{\Pi_{t+k}}\right)^{1-\theta}-\frac{\theta}{\alpha(\theta-1)} y_{t+j}^{\gamma}\left(b_{t} \prod_{k=1}^{j} \frac{1}{\Pi_{t+k}}\right)^{-\theta / \alpha} d_{t+j}^{1 / \eta}\right], \\
d_{t} & =(1-\lambda) b_{t}^{-\theta / \alpha}+\lambda \Pi_{t}^{\theta / \alpha} d_{t-1},
\end{aligned}
$$

and the steady state with trend inflation $\bar{\Pi}$ is given by

$$
\begin{aligned}
& R=\frac{\bar{\Pi} \exp (g)}{\beta}, \quad b=\left(\frac{1-\lambda \bar{\Pi}^{\theta-1}}{1-\lambda}\right)^{1 /(1-\theta)}, \quad d=\frac{1-\lambda}{1-\lambda \bar{\Pi}^{\theta / \alpha}} b^{-\theta / \alpha}, \\
& y=\left[\frac{\alpha(\theta-1)}{\theta} \frac{1-\beta \lambda \bar{\Pi}^{\theta / \alpha}}{1-\beta \lambda \bar{\Pi}^{\theta-1}} b^{1+\theta(1 / \alpha-1)} d^{-1 / \eta}\right]^{1 / \gamma} .
\end{aligned}
$$




\section{B DERIVATION OF GENERALIZED NEW KEYNESIAN PHILLIPS CURVES (13) AND (19)}

This appendix presents the derivation of the GNKPC (13) and (19).

In the model with firm-specific labor, log-linearizing the equilibrium conditions (43) and (44) yields

$$
\begin{aligned}
\hat{b}_{t}= & \frac{1-\theta}{1+\theta(\gamma-1)} \sum_{j=1}^{\infty}\left(\beta \lambda \bar{\Pi}^{\theta-1}\right)^{j} E_{t} \hat{\Pi}_{t+j}+\frac{\theta \gamma}{1+\theta(\gamma-1)} \sum_{j=1}^{\infty}\left(\beta \lambda \bar{\Pi}^{\theta \gamma}\right)^{j} E_{t} \hat{\Pi}_{t+j} \\
& +\frac{1-\beta \lambda \bar{\Pi}^{\theta \gamma}}{1+\theta(\gamma-1)} \sum_{j=0}^{\infty}\left(\beta \lambda \bar{\Pi}^{\theta \gamma}\right)^{j}\left(\gamma E_{t} \hat{y}_{t+j}+E_{t} \varepsilon_{t+j}\right)-\frac{1-\beta \lambda \bar{\Pi}^{\theta-1}}{1+\theta(\gamma-1)} \sum_{j=0}^{\infty}\left(\beta \lambda \bar{\Pi}^{\theta-1}\right)^{j} E_{t} \varepsilon_{t+j}, \\
\hat{b}_{t}= & \frac{\lambda \bar{\Pi}^{\theta-1}}{1-\lambda \bar{\Pi}^{\theta-1}} \hat{\Pi}_{t} .
\end{aligned}
$$

Combining these equations and taking a first difference of the resulting equation yields

$$
\begin{aligned}
\hat{\Pi}_{t}= & \beta E_{t} \hat{\Pi}_{t+1}+\frac{\gamma\left(1-\lambda \bar{\Pi}^{\theta-1}\right)\left(1-\beta \lambda \bar{\Pi}^{\theta \gamma}\right)}{\lambda \bar{\Pi}^{\theta-1}[1+\theta(\gamma-1)]} \hat{y}_{t}-\frac{\beta\left(\bar{\Pi}^{1+\theta(\gamma-1)}-1\right)\left(1-\lambda \bar{\Pi}^{\theta-1}\right)}{1+\theta(\gamma-1)} \varepsilon_{t} \\
& +\frac{\theta \gamma\left(1-\bar{\Pi}^{-[1+\theta(\gamma-1)]}\right)\left(1-\lambda \bar{\Pi}^{\theta-1}\right)}{\lambda \bar{\Pi}^{\theta-1}[1+\theta(\gamma-1)]} \sum_{j=1}^{\infty}\left(\beta \lambda \bar{\Pi}^{\theta \gamma}\right)^{j} E_{t} \hat{\Pi}_{t+j} \\
& +\frac{\left(1-\bar{\Pi}^{-[1+\theta(\gamma-1)]}\right)\left(1-\lambda \bar{\Pi}^{\theta-1}\right)\left(1-\beta \lambda \bar{\Pi}^{\theta \gamma}\right)}{\lambda \bar{\Pi}^{\theta-1}[1+\theta(\gamma-1)]} \sum_{j=1}^{\infty}\left(\beta \lambda \bar{\Pi}^{\theta \gamma}\right)^{j}\left(\gamma E_{t} \hat{y}_{t+j}+E_{t} \varepsilon_{t+j}\right)
\end{aligned}
$$

Taking a first difference of this equation leads to the GNKPC (13).

In the model with homogeneous labor, log-linearizing the equilibrium condition (46) yields

$$
\begin{aligned}
\hat{b}_{t}= & \frac{1-\theta}{1+\theta(1 / \alpha-1)} \sum_{j=1}^{\infty}\left(\beta \lambda \bar{\Pi}^{\theta-1}\right)^{j} E_{t} \hat{\Pi}_{t+j}+\frac{1}{1+\theta(1 / \alpha-1)} \sum_{j=1}^{\infty}\left(\beta \lambda \bar{\Pi}^{\theta / \alpha}\right)^{j} \frac{\theta}{\alpha} E_{t} \hat{\Pi}_{t+j} \\
& +\frac{1-\beta \lambda \bar{\Pi}^{\theta / \alpha}}{1+\theta(1 / \alpha-1)} \sum_{j=0}^{\infty}\left(\beta \lambda \bar{\Pi}^{\theta / \alpha}\right)^{j}\left(\gamma E_{t} \hat{y}_{t+j}+\frac{1}{\eta} E_{t} \hat{d}_{t+j}+E_{t} \varepsilon_{t+j}\right)-\frac{1-\beta \lambda \bar{\Pi}^{\theta-1}}{1+\theta(1 / \alpha-1)} \sum_{j=0}^{\infty}\left(\beta \lambda \bar{\Pi}^{\theta-1}\right)^{j} E_{t} \varepsilon_{t+j}
\end{aligned}
$$

Combining this equation and (47) and taking a first difference of the resulting equation yields

$$
\begin{aligned}
\hat{\Pi}_{t}= & \beta E_{t} \hat{\Pi}_{t+1}+\frac{\gamma\left(1-\lambda \bar{\Pi}^{\theta-1}\right)\left(1-\beta \lambda \bar{\Pi}^{\theta / \alpha}\right)}{\lambda \bar{\Pi}^{\theta-1}[1+\theta(1 / \alpha-1)]}\left(\hat{y}_{t}+\frac{1}{\eta \gamma} \hat{d}_{t}\right)-\frac{\beta\left(\bar{\Pi}^{1+\theta(1 / \alpha-1)}-1\right)\left(1-\lambda \bar{\Pi}^{\theta-1}\right)}{1+\theta(1 / \alpha-1)} \varepsilon_{t} \\
& +\frac{\left(1-\bar{\Pi}^{-[1+\theta(1 / \alpha-1)]}\right)\left(1-\lambda \bar{\Pi}^{\theta-1}\right)}{\lambda \bar{\Pi}^{\theta-1}[1+\theta(1 / \alpha-1)]} \sum_{j=1}^{\infty}\left(\beta \lambda \bar{\Pi}^{\theta / \alpha}\right)^{j} \frac{\theta}{\alpha} E_{t} \hat{\Pi}_{t+j} \\
& +\frac{\left(1-\bar{\Pi}^{-[1+\theta(1 / \alpha-1)]}\right)\left(1-\lambda \bar{\Pi}^{\theta-1}\right)\left(1-\beta \lambda \bar{\Pi}^{\theta / \alpha}\right)}{\lambda \bar{\Pi}^{\theta-1}[1+\theta(1 / \alpha-1)]} \sum_{j=1}^{\infty}\left(\beta \lambda \bar{\Pi}^{\theta / \alpha}\right)^{j}\left(\gamma E_{t} \hat{y}_{t+j}+\frac{1}{\eta} E_{t} \hat{d}_{t+j}+E_{t} \varepsilon_{t+j}\right) .
\end{aligned}
$$

Taking a first difference of this equation leads to the GNKPC (19). 


\section{COEFFICIENT MATRICES IN SYSTEMS (21) AND}

In the system (21), the coefficient matrix $A$ is given by

$$
A=\left[A_{j k}\right]=\left[\begin{array}{ccc}
A_{11} & A_{12} & A_{13} \\
\frac{1-\phi_{\pi} A_{11}}{1+\phi_{y}} & \frac{1-\phi_{\pi} A_{12}}{1+\phi_{y}} & -\frac{\phi_{\pi} A_{13}}{1+\phi_{y}} \\
1 & 0 & 0
\end{array}\right],
$$

where

$$
\begin{aligned}
& A_{11}=\frac{\kappa_{f}[1+\theta(\gamma-1)]+\beta\left(1+\phi_{y}\right)\left\{\left(1+\lambda \bar{\Pi}^{\theta \gamma}\right)[1+\theta(\gamma-1)]+\theta \gamma\left(\bar{\Pi}^{1+\theta(\gamma-1)}-1\right)\left(1-\lambda \bar{\Pi}^{\theta-1}\right)\right\}}{\left(\phi_{y}+1+\kappa_{f} \phi_{\pi}\right)[1+\theta(\gamma-1)]}, \\
& A_{12}=\frac{\kappa_{f}\left[1-\beta \lambda \bar{\Pi}^{\theta-1}\left(1+\phi_{y}\right)\right]}{\phi_{y}+1+\kappa_{f} \phi_{\pi}}, \quad A_{13}=-\frac{\beta^{2} \lambda \bar{\Pi}^{\theta \gamma}\left(1+\phi_{y}\right)}{\phi_{y}+1+\kappa_{f} \phi_{\pi}} .
\end{aligned}
$$

In the system (29), the coefficient matrix $C$ and vector $D$ are given by the submatrices of $A: C=\left[A_{j k}\right]$ and $D=\left[A_{j 3}\right]$ for $j=1,2$ and $k=1,2$.

\section{PROOF OF PROPOSITIONS 1-4}

This appendix presents the proof of Propositions 1-4.

\section{D.1 Proof of Proposition 1}

The characteristic equation for the coefficient matrix $A$ of the system (21) is given by

$$
\mu^{3}+a_{2} \mu^{2}+a_{1} \mu+a_{0}=0
$$

where

$$
a_{2}=-\frac{1}{1+\phi_{y}}-A_{11}+\frac{\phi_{\pi}}{1+\phi_{y}} A_{12}, \quad a_{1}=\frac{1}{1+\phi_{y}} A_{11}-\frac{1}{1+\phi_{y}} A_{12}-A_{13}, \quad a_{0}=\frac{1}{1+\phi_{y}} A_{13} .
$$

The REE is determinate if and only if all eigenvalues of the coefficient matrix $A$ are inside the unit circle. Thus the necessary and sufficient condition for determinacy of the REE is that all solutions to the characteristic equation are less than unity in absolute value. By the Cohn-Schur criterion (see, e.g., Gandolfo, 1997), the necessary and sufficient condition for determinacy is that the three inequalities hold: $1+a_{2}+a_{1}+a_{0}>0,1-a_{2}+a_{1}-a_{0}>0$, and $\left(a_{0}\right)^{2}-a_{0} a_{2}+a_{1}-1<0$. The first inequality can be reduced to the long-run version of the Taylor principle (22). It can be shown that the second one is satisfied under Assumption 1. The third one can be reduced to the condition (23). 


\section{D.2 Proof of Proposition 2}

The fundamental REE is E-stable if and only if all eigenvalues of two matrices, $D T_{c}(\bar{c}, \bar{\Gamma})=$ $C+D\left[\begin{array}{ll}1 & 0\end{array}\right]$ and $D T_{\Gamma}(\bar{c}, \bar{\Gamma})=\rho\left(C+\rho D\left[\begin{array}{ll}1 & 0\end{array}\right]\right)$, have real parts less than unity. Thus the necessary and sufficient condition for E-stability of the fundamental REE is that all eigenvalues of two matrices, $\left(C+D\left[\begin{array}{ll}1 & 0\end{array}\right]-I\right)$ and $\left(\rho\left(C+\rho D\left[\begin{array}{ll}1 & 0\end{array}\right]\right)-I\right)$, have negative real parts. The characteristic equations of these two matrices are given by

$$
\mu^{2}+a_{1} \mu+a_{0}=0, \quad \mu^{2}+a_{3} \mu+a_{2}=0,
$$

where

$$
\begin{aligned}
& a_{0}=\frac{\phi_{y}}{1+\phi_{y}}-\frac{\phi_{y}}{1+\phi_{y}} A_{11}+\frac{\phi_{\pi}-1}{1+\phi_{y}} A_{12}-\frac{\phi_{y}}{1+\phi_{y}} A_{13}, \quad a_{1}=\frac{1+2 \phi_{y}}{1+\phi_{y}}-A_{11}+\frac{\phi_{\pi}}{1+\phi_{y}} A_{12}-A_{13}, \\
& a_{2}=\frac{1-\rho+\phi_{y}}{1+\phi_{y}}-\frac{\rho\left(1-\rho-\phi_{y}\right)}{1+\phi_{y}} A_{11}+\frac{\rho\left(\phi_{\pi}-\rho\right)}{1+\phi_{y}} A_{12}-\frac{\rho^{2}\left(1-\rho+\phi_{y}\right)}{1+\phi_{y}} A_{13}, \\
& a_{3}=\frac{2-\rho+2 \phi_{y}}{1+\phi_{y}}-\rho A_{11}+\frac{\rho \phi_{\pi}}{1+\phi_{y}} A_{12}-\rho^{2} A_{13} .
\end{aligned}
$$

By the Routh-Hurwitz theorem (see, e.g., Samuelson, 1947), the necessary and sufficient condition for E-stability is that the four inequalities $a_{j}>0, j=0,1,2,3$ are satisfied. The first three inequalities can be reduced to the long-run version of the Taylor principle (22) and the other two conditions (33) and (34), respectively. It can be shown that the remaining inequality $a_{3}>0$ is implied by the inequality $a_{1}>0$ (i.e., (33)), because $0 \leq \rho<1$.

\section{D.3 Proof of Proposition 3}

In the case of the forecast-based Taylor rule (35), the system of the log-linearized equilibrium conditions takes the same form as (21), with the coefficient matrix given by

$$
A=\left[A_{j k}\right]=\left[\begin{array}{ccc}
A_{11} & A_{12} & A_{13} \\
1-\phi_{\pi} & 1-\phi_{y} & 0 \\
1 & 0 & 0
\end{array}\right]=\left[\begin{array}{ccc}
A_{11} & \kappa_{f}\left(1-\beta \lambda \bar{\Pi}^{\theta-1}-\phi_{y}\right) & -\beta^{2} \lambda \bar{\Pi}^{\theta \gamma} \\
1-\phi_{\pi} & 1-\phi_{y} & 0 \\
1 & 0 & 0
\end{array}\right]
$$

where

$$
A_{11}=\beta\left(1+\lambda \bar{\Pi}^{\theta \gamma}\right)+\frac{\beta \theta \gamma\left(\bar{\Pi}^{1+\theta(\gamma-1)}-1\right)\left(1-\lambda \bar{\Pi}^{\theta-1}\right)}{1+\theta(\gamma-1)}+\kappa_{f}\left(1-\phi_{\pi}\right) .
$$

The characteristic equation of the system's coefficient matrix $A$ is given by

$$
\mu^{3}+a_{2} \mu^{2}+a_{1} \mu+a_{0}=0
$$


where

$$
a_{2}=-\left(1-\phi_{y}\right)-A_{11}, \quad a_{1}=\left(1-\phi_{y}\right) A_{11}+\left(\phi_{\pi}-1\right) A_{12}-A_{13}, \quad a_{0}=\left(1-\phi_{y}\right) A_{13} .
$$

The REE is determinate if and only if all eigenvalues of the coefficient matrix $A$ are inside the unit circle. Thus the necessary and sufficient condition for determinacy of the REE is that all solutions to the characteristic equation are less than unity in absolute value. By the Cohn-Schur criterion, the necessary and sufficient condition for determinacy is that the three inequalities hold: $1+a_{2}+a_{1}+a_{0}>0,1-a_{2}+a_{1}-a_{0}>0$, and $\left(a_{0}\right)^{2}-a_{0} a_{2}+a_{1}-1<0$. These three inequalities can be reduced to the long-run version of the Taylor principle (22) and the other two conditions (36) and (37), respectively.

\section{D.4 Proof of Proposition 4}

In the case of the forecast-based Taylor rule (35), the system of the log-linearized equilibrium conditions takes the same form as (29), with the coefficient matrix $C$ and vector $D$ that are the submatrices of $A$ given in Appendix D.3: $C=\left[A_{j k}\right]$ and $D=\left[A_{j 3}\right]$ for $j=1,2$ and $k=1,2$. The fundamental REE is E-stable if and only if all eigenvalues of two matrices, $D T_{c}(\bar{c}, \bar{\Gamma})=C+D\left[\begin{array}{ll}1 & 0\end{array}\right]$ and $D T_{\Gamma}(\bar{c}, \bar{\Gamma})=\rho\left(C+\rho D\left[\begin{array}{ll}1 & 0\end{array}\right]\right)$, have real parts less than unity. Thus the necessary and sufficient condition for E-stability of the fundamental REE is that all eigenvalues of two matrices, $\left(C+D\left[\begin{array}{ll}1 & 0\end{array}\right]-I\right)$ and $\left(\rho\left(C+\rho D\left[\begin{array}{ll}1 & 0\end{array}\right]\right)-I\right)$, have negative real parts. The characteristic equations of these two matrices are given by

$$
\mu^{2}+a_{1} \mu+a_{0}=0, \quad \mu^{2}+a_{3} \mu+a_{2}=0,
$$

where

$a_{0}=\phi_{y}-\phi_{y} A_{11}+\left(\phi_{\pi}-1\right) A_{12}-\phi_{y} A_{13}, \quad a_{1}=\phi_{y}+1-A_{11}-A_{13}, \quad a_{2}=2-\rho+\rho \phi_{y}-\rho A_{11}-\rho^{2} A_{13}$,

$a_{3}=1-\rho+\rho \phi_{y}-\rho\left(1-\rho+\rho \phi_{y}\right) A_{11}+\rho^{2}\left(\phi_{\pi}-1\right) A_{12}-\rho^{2}\left(1-\rho+\rho \phi_{y}\right) A_{13}$.

By the Routh-Hurwitz theorem, the necessary and sufficient condition for E-stability is that the four inequalities $a_{j}>0, j=0,1,2,3$ are satisfied. The first three inequalities can be reduced to the long-run version of the Taylor principle (22) and the other two conditions (38) and (39), respectively. It can be shown that the remaining inequality $a_{3}>0$ is implied by the inequality $a_{1}>0$ (i.e., (38)), because $0 \leq \rho<1$. 


\section{References}

[1] Altig, David, Lawrence J. Christiano, Martin Eichenbaum, and Jesper Lindé (2011) Firmspecific capital, nominal rigidities and the business cycle. Review of Economic Dynamics $14(2), 225-247$.

[2] Arias, Jonas (2013) Determinacy properties of medium-sized new-Keynesian models with trend inflation. Mimeo.

[3] Ascari, Guido and Tiziano Ropele (2007) Optimal monetary policy under low trend inflation. Journal of Monetary Economics 54(8), 2568-2583.

[4] Ascari, Guido and Tiziano Ropele (2009) Trend inflation, Taylor principle and indeterminacy. Journal of Money, Credit and Banking, 41(8), 1557-1584.

[5] Ascari, Guido and Argia M. Sbordone (2014) The macroeconomics of trend inflation. Journal of Economic Literature 52(3), 679-739.

[6] Ball, Laurence, N. Gregory Mankiw, and David Romer (1988) The new Keynesian economics and the output-inflation trade-off. Brookings Papers on Economic Activity 19(1), $1-65$.

[7] Bakhshi, Hasan, Hashmat Khan, Pablo Burriel-Llombart, and Barbara Rudolf (2007) The new Keynesian Phillips curve under trend inflation and strategic complementarity. Journal of Macroeconomics 29(1), 37-59.

[8] Bullard, James and Kaushik Mitra (2002) Learning about monetary policy rules. Journal of Monetary Economics 49(6), 1105-1129

[9] Calvo, Guillermo A. (1983) Staggered prices in a utility-maximizing framework. Journal of Monetary Economics 12(3), 383-398.

[10] Clarida, Richard, Jordi Galí, and Mark Gertler (2000) Monetary policy rules and macroeconomic stability: evidence and some theory. Quarterly Journal of Economics 115(1), 147180.

[11] Cogley, Timothy and Argia M. Sbordone (2008) Trend inflation, indexation, and inflation persistence in the new Keynesian Phillips curve. American Economic Review 98(5), 21012126. 
[12] Coibion, Olivier and Yuriy Gorodnichenko (2011) Monetary policy, trend inflation and the Great Moderation: an alternative interpretation. American Economic Review 101(1), $341-370$.

[13] Devereux, Michael B. and James Yetman (2002) Menu costs and the long-run outputinflation trade-off. Economics Letters 76(1), 95-100.

[14] Eichenbaum, Martin and Jonas D. M. Fisher (2007) Estimating the frequency of price re-optimization in Calvo-style models. Journal of Monetary Economics 54(7), 2032-2047.

[15] Evans, George W. and Seppo Honkapohja (2001) Learning and Expectations in Macroeconomics. Princeton, NJ: Princeton University Press.

[16] Gandolfo, Giancarlo (1997) Economic Dynamics: Study Edition. Berlin: Springer-Verlag.

[17] Honkapohja, Seppo, Kaushik Mitra, and George W. Evans (2011) Notes on agent's behavioral rules under adaptive learning and studies of monetary policy. CDMA Working Paper 11/02, University of St. Andrews.

[18] Hornstein, Andreas and Alexander L. Wolman (2005) Trend inflation, firm-specific capital, and sticky prices. Federal Reserve Bank of Richmond, Economic Quarterly Fall issue.

[19] Kehoe, Patrick J. and Virgiliu Midrigan (2015) Prices are sticky after all. Journal of Monetary Economics, forthcoming.

[20] Kiley, Michael T. (2000) Endogenous price stickiness and business cycle persistence. Journal of Money, Credit, and Banking 32(1), 28-53.

[21] Kiley, Michael T. (2007) Is moderate-to-high inflation inherently unstable? International Journal of Central Banking 3(2), 173-201.

[22] Kimura, Takeshi and Takushi Kurozumi (2010) Endogenous nominal rigidities and monetary policy. Journal of Monetary Economics 57(8), 1038-1048.

[23] Klenow, Peter J. and Oleksiy Kryvtsov (2008) State-dependent or time-dependent pricing: does it matter for recent U.S. inflation? Quarterly Journal of Economics, 123(3), 863-904.

[24] Klenow, Peter J. and Benjamin A. Malin (2010) Microeconomic evidence on price-setting. In Handbook of Monetary Economics, Vol. 3, Benjamin M. Friedman and Michael Woodford, eds., Amsterdam: Elsevier, North-Holland, 231-284. 
[25] Kobayashi, Teruyoshi and Ichiro Muto (2013) A note on expectational stability under nonzero trend inflation. Macroeconomic Dynamics 17(3), 681-693.

[26] Kurozumi, Takushi (2006) Determinacy and expectational stability of equilibrium in a monetary sticky-price model with Taylor rule. Journal of Monetary Economics 53(4), 827846.

[27] Kurozumi, Takushi (2011) Endogenous price stickiness, trend inflation, and macroeconomic stability. Mimeo.

[28] Kurozumi, Takushi (2014) Trend inflation, sticky prices, and expectational stability. Journal of Economic Dynamics and Control 42, 175-187.

[29] Kurozumi, Takushi and Willem Van Zandweghe (2008) Investment, interest rate policy, and equilibrium stability. Journal of Economic Dynamics and Control 32(5), 1489-1516.

[30] Kurozumi, Takushi and Willem Van Zandweghe (2012) Learning about monetary policy rules when labor market search and matching frictions matter. Journal of Economic Dynamics and Control 36(4), 523-535.

[31] Levin, Andrew T., J. David López-Salido, Edward Nelson, and Tack Yun (2008) Macroeconomic equivalence, microeconomic dissonance, and the design of monetary policy. Journal of Monetary Economics 55, S48-S62.

[32] Levin, Andrew T. and Tack Yun (2007) Reconsidering the natural rate hypothesis in a new Keynesian framework. Journal of Monetary Economics 54(5), 1344-1365.

[33] Lubik, Thomas A. and Frank Schorfheide (2004) Testing for indeterminacy: an application to U.S. monetary policy. American Economic Review 94(1), 190-217.

[34] McCallum, Bennett T. (1983) On non-uniqueness in linear rational expectations models: an attempt at perspective. Journal of Monetary Economics 11(2), 139-168.

[35] McCallum, Bennett T. (2007) E-stability vis-a-vis determinacy results for a broad class of linear rational expectations models. Journal of Economic Dynamics and Control 31(4), $1376-1391$.

[36] Nakamura, Emi and Jon Steinsson (2008) Five facts about prices: a reevaluation of menu cost models. Quarterly Journal of Economics 123(4), 1415-1464. 
[37] Romer, David (1990) Staggered price setting with endogenous frequency of adjustment. Economics Letters 32(3), 205-210.

[38] Samuelson, Paul A. (1947) Foundations of Economic Analysis. Cambridge, MA: Harvard University Press.

[39] Sbordone, Argia M. (2007) Inflation persistence: alternative interpretations and policy implications. Journal of Monetary Economics 54(5), 1311-1339.

[40] Sveen, Tommy and Lutz Weinke (2005) New perspectives on capital, sticky prices, and the Taylor principle. Journal of Economic Theory 123(1), 21-39.

[41] Sveen, Tommy and Lutz Weinke (2007) Firm-specific capital, nominal rigidities, and the Taylor principle. Journal of Economic Theory 136(1), 729-737.

[42] Taylor, John B. (1980) Aggregate dynamics and staggered contracts. Journal of Political Economy 88(1), 1-22.

[43] Taylor, John B. (1993) Discretion versus policy rules in practice. Carnegie-Rochester Conference Series on Public Policy 39(1), 195-214.

[44] Woodford, Michael (2003) Interest and Prices. Foundations of a Theory of Monetary Policy. Princeton, NJ: Princeton University Press.

[45] Woodford, Michael (2005) Firm-specific capital and the new Keynesian Phillips curve. International Journal of Central Banking 1(2), 1-46. 
Table 1: Calibration of parameters for the quarterly model

\begin{tabular}{lll}
\hline$\beta$ & Subjective discount factor & 0.99 \\
$\eta$ & Elasticity of labor supply & 1 \\
$\theta$ & Price elasticity of demand for differentiated goods & 10 \\
$\alpha$ & Labor elasticity of output & 1 \\
$\lambda$ & Probability of no price adjustment & 0.55 \\
$\rho$ & Persistence of preference shocks & 0.35 \\
\hline
\end{tabular}



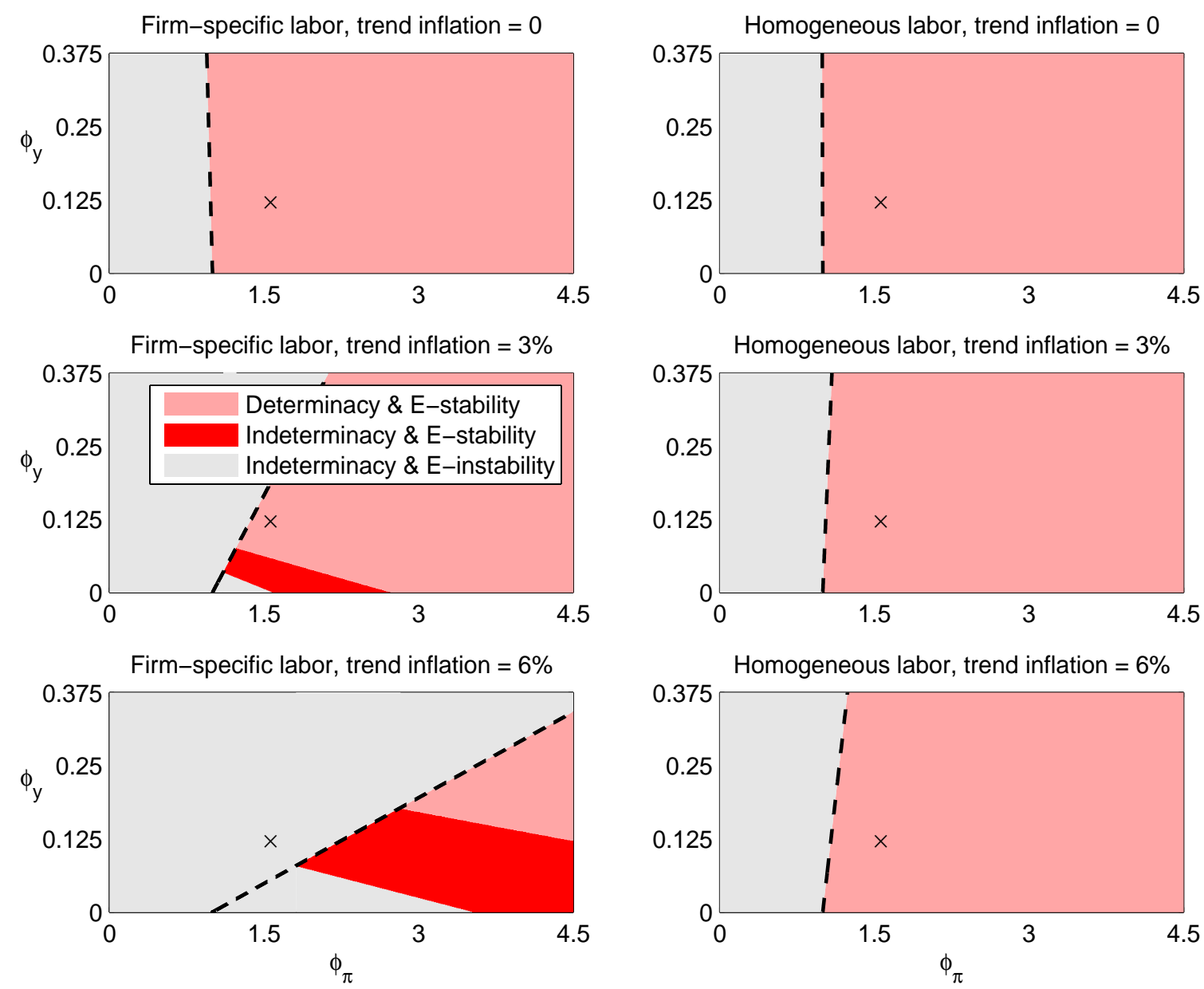

Figure 1: Regions of the inflation and output coefficients $\left(\phi_{\pi}, \phi_{y}\right)$ of the Taylor rule (14) that guarantee determinacy of the REE and E-stability of the fundamental REE.

Notes: In the left column, the results of the model with firm-specific labor at an annualized trend inflation rate of zero, three, and six percent are presented and the dashed line represents the boundary defined by the long-run version of the Taylor principle (22). In the right column, the results of the model with homogeneous labor are presented and the dashed line is the boundary defined by the long-run version of the Taylor principle (28). In each panel the mark “×” shows Taylor (1993)'s estimates $\left(\phi_{\pi}, \phi_{y}\right)=(1.5,0.5 / 4)$. 


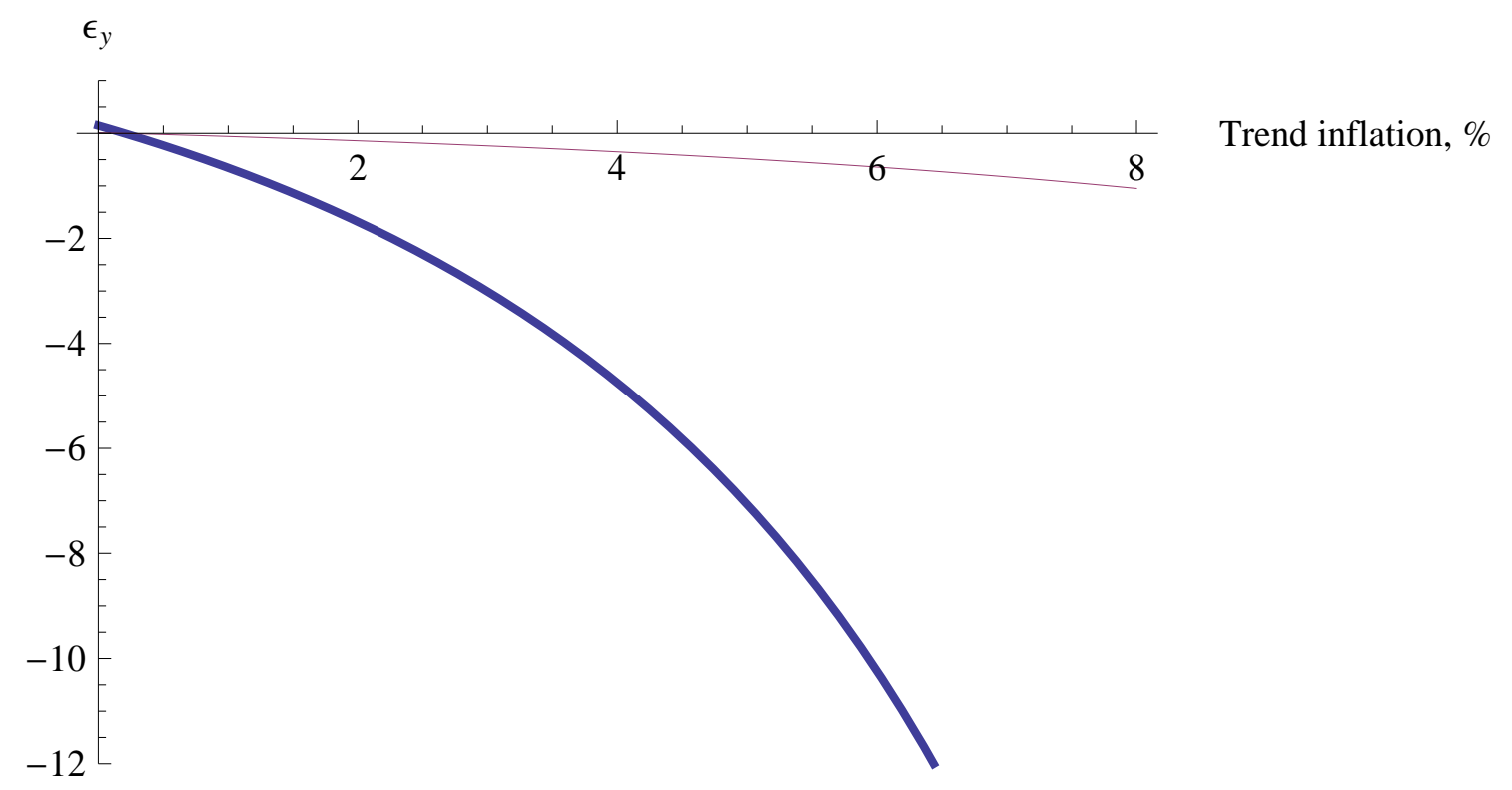

Figure 2: Effect of the level of trend inflation on the long-run inflation elasticity of output $\epsilon_{y}$. Note: The thick and thin lines illustrate the models with firm-specific labor and with homogeneous labor, respectively. 

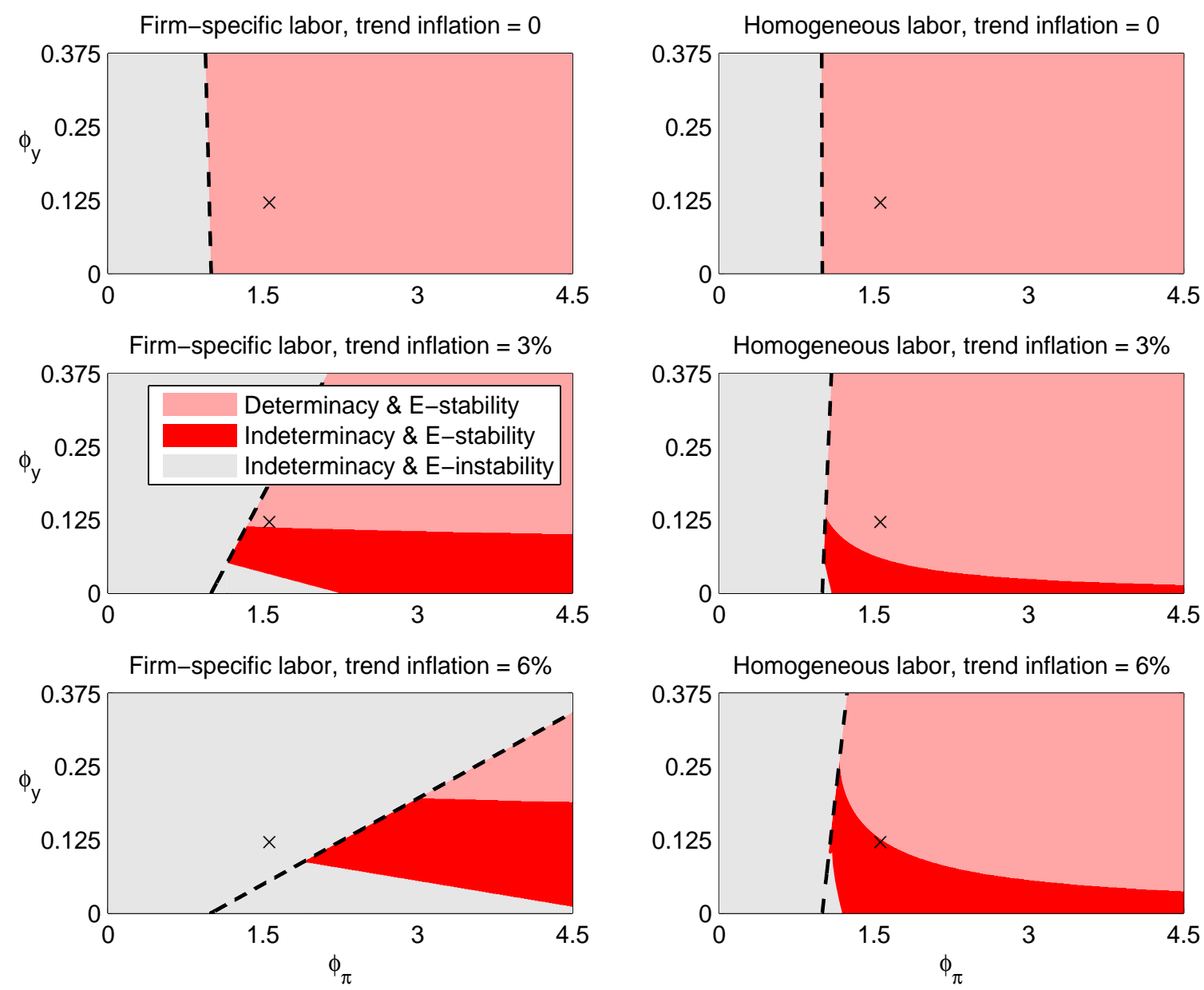

Figure 3: Regions of the inflation and output coefficients $\left(\phi_{\pi}, \phi_{y}\right)$ of the forecast-based Taylor rule (35) that guarantee determinacy of the REE and E-stability of the fundamental REE.

Notes: In the left column, the results of the model with firm-specific labor at an annualized trend inflation rate of zero, three, and six percent are presented and the dashed line represents the boundary defined by the long-run version of the Taylor principle (22). In the right column, the results of the model with homogeneous labor are presented and the dashed line is the boundary defined by the long-run version of the Taylor principle (28). In each panel the mark “×” shows Taylor (1993)'s estimates $\left(\phi_{\pi}, \phi_{y}\right)=(1.5,0.5 / 4)$. 

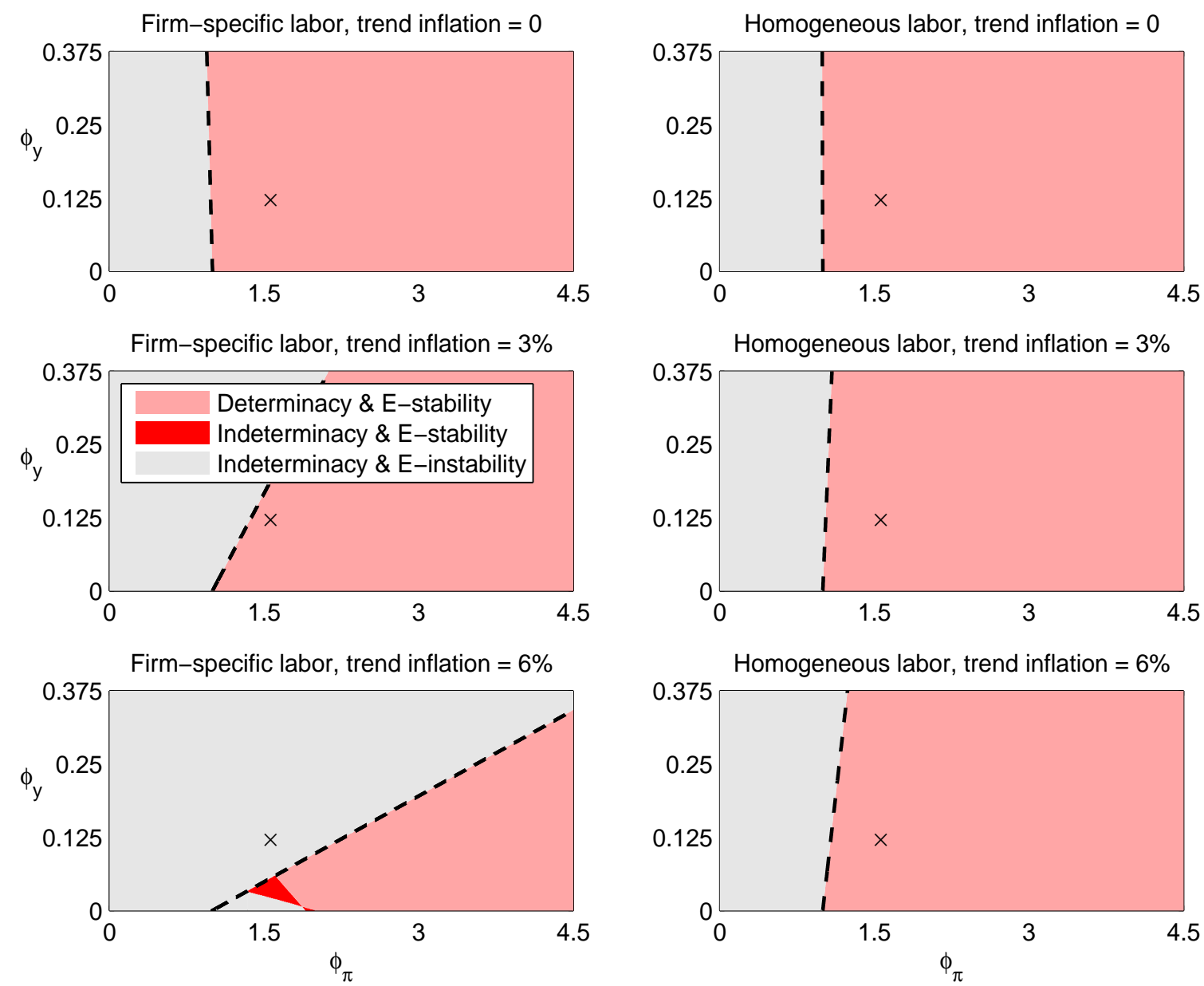

Figure 4: Regions of the inflation and output coefficients $\left(\phi_{\pi}, \phi_{y}\right)$ of the Taylor rule with policy rate smoothing (40) that guarantee determinacy of the REE and E-stability of the fundamental REE.

Notes: In the left column, the results of the model with firm-specific labor at an annualized trend inflation rate of zero, three, and six percent are presented and the dashed line represents the boundary defined by the long-run version of the Taylor principle (22). In the right column, the results of the model with homogeneous labor are presented and the dashed line is the boundary defined by the long-run version of the Taylor principle (28). In each panel the mark " $\times "$ shows Taylor (1993)'s estimates $\left(\phi_{\pi}, \phi_{y}\right)=(1.5,0.5 / 4)$. 

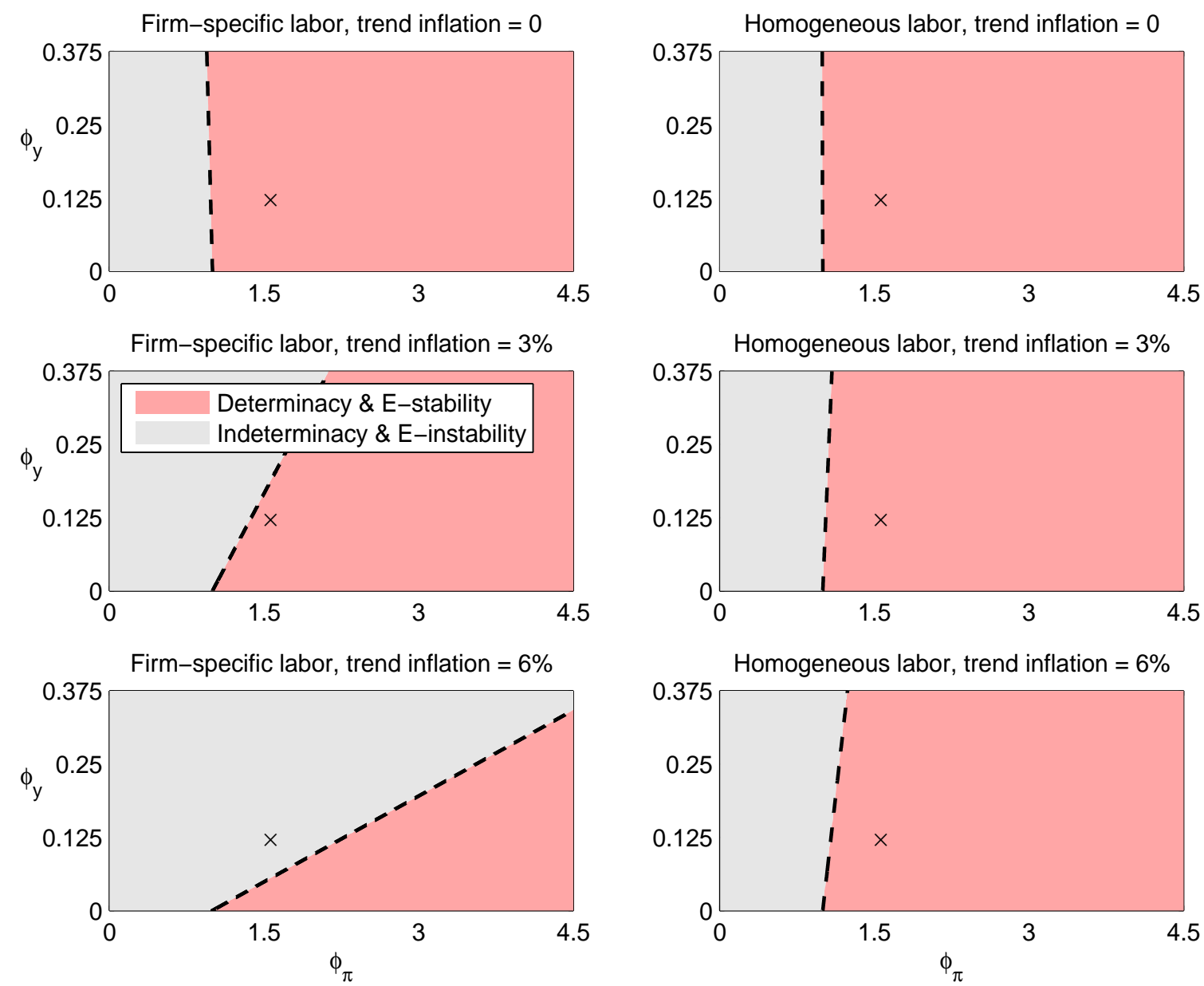

Figure 5: Regions of the inflation and output coefficients $\left(\phi_{\pi}, \phi_{y}\right)$ of the Taylor rule with responses to output growth (41) that guarantee determinacy of the REE and E-stability of the fundamental REE.

Notes: In the left column, the results of the model with firm-specific labor at an annualized trend inflation rate of zero, three, and six percent are presented and the dashed line represents the boundary defined by the long-run version of the Taylor principle (22). In the right column, the results of the model with homogeneous labor are presented and the dashed line is the boundary defined by the long-run version of the Taylor principle (28). In each panel the mark “×” shows Taylor (1993)'s estimates $\left(\phi_{\pi}, \phi_{y}\right)=(1.5,0.5 / 4)$. 

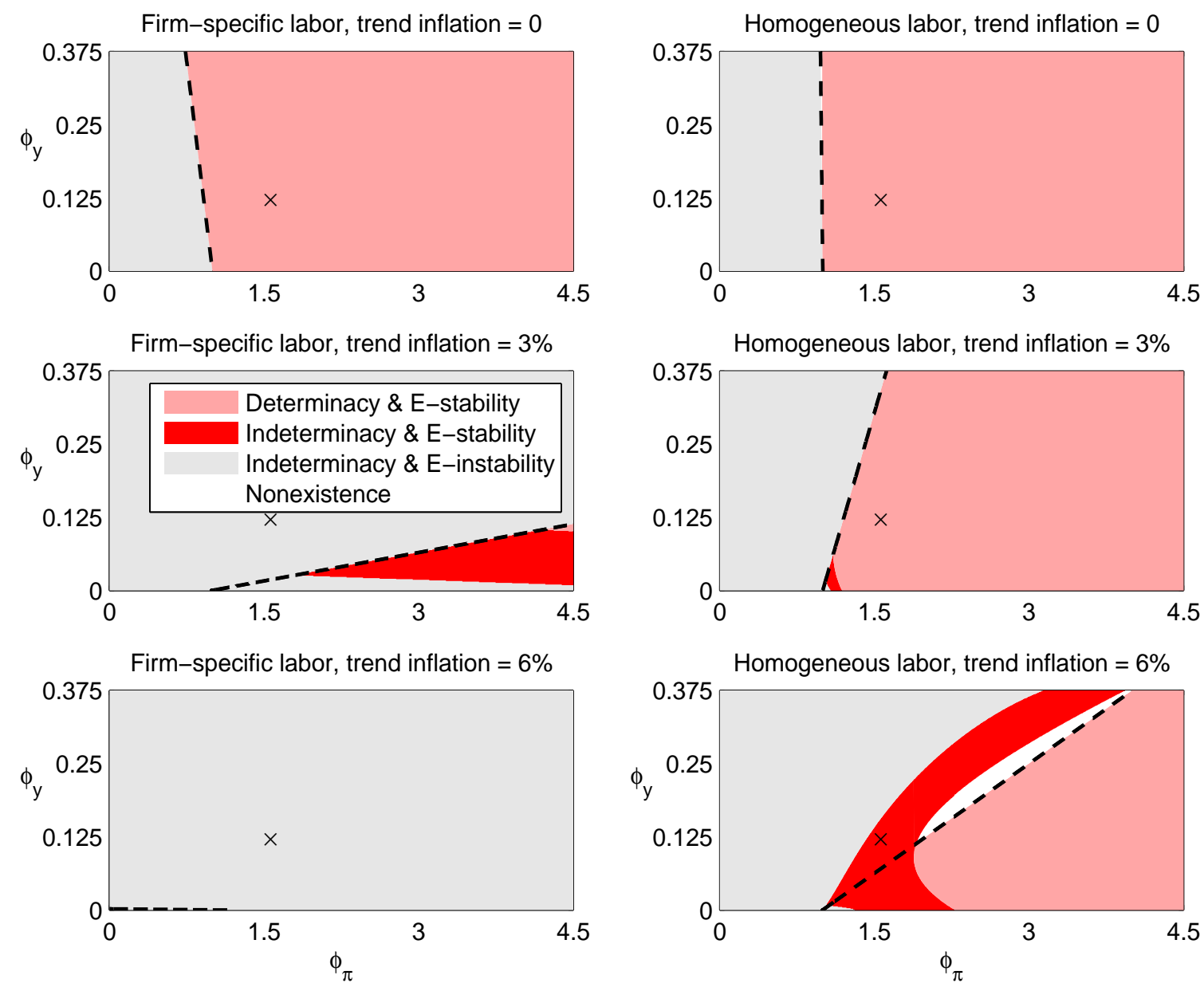

Figure 6: Regions of the inflation and output coefficients $\left(\phi_{\pi}, \phi_{y}\right)$ of the Taylor rule (14) that guarantee determinacy of the REE and E-stability of the fundamental REE under the calibration of Ascari and Ropele (2009).

Notes: In the left column, the results of the model with firm-specific labor at an annualized trend inflation rate of zero, three, and six percent are presented and the dashed line represents the boundary defined by the long-run version of the Taylor principle (22). In the right column, the results of the model with homogeneous labor are presented and the dashed line is the boundary defined by the long-run version of the Taylor principle (28). In each panel the mark “×” shows Taylor (1993)'s estimates $\left(\phi_{\pi}, \phi_{y}\right)=(1.5,0.5 / 4)$. 